\title{
Time-Varying and Regional Dynamics in Swiss Housing Markets ${ }^{a}$
}

\author{
Dirk Drechsel ${ }^{b}$ and Anne Kathrin Funk ${ }^{c}$
}

JEL-Classification: C32, R21, R31

Keywords: Switzerland, house prices, time-varying BVAR

\section{SUMMARY}

In light of the strong increase of house prices in Switzerland in the 2000s and early 2010s, we analyze the effects of mortgage rate shocks, changes in housing demand \& supply and business cycle conditions on house prices for the time period 1982-2013. We study intertemporal effects by employing Bayesian timevarying coefficients vector autoregressions (TVC-BVAR), regional effects by using regional BVARs and heterogeneity in housing markets by looking at housing segments. $50 \%$ of house price variations can be explained by housing demand $\&$ supply. The response of house prices to mortgage rate shocks weakened after the 1990s real estate crisis and remained constant thereafter. However, owneroccupied apartment prices became again more sensitive to mortgage rate shocks during the recent house price boom. Regional effects are especially prevalent for regions Zurich and Geneva.

a We are grateful to Klaus Abberger, Samad Sarferaz, Jan-Egbert Sturm and Cédric Tille for valuable comments and discussions. We further thank Florian Eckert for valuable research assistance and seminar participants at ETH Zurich and the Geneva Graduate Institute of International and Development Studies as well as two anonymous referees for helpful comments.

b KOF Swiss Economic Institute, ETH Zurich, Leonhardstrasse 21, 8092 Zurich, Switzerland, Email: drechsel@kof.ethz.ch.

c KOF Swiss Economic Institute, ETH Zurich, Leonhardstrasse 21, 8092 Zurich, Switzerland and Graduate Institute of International and Development Studies, Maison de la Paix, Chémin Eugen-Rigot 2, 1202 Geneva, Switzerland, Email: funk@kof.ethz.ch. 


\section{Introduction}

Residential house prices have displayed a rapid growth in the late 2000s and early 2010s and start to resemble the development they went through in the late $1980 \mathrm{~s}$ and early 1990s when the exaggerated inflation of residential prices ended in a bust of the housing market. An important question when dealing with a booming residential housing market is to determine to which extent the current price movements can be explained by the development of fundamentals, if reactions to changes of these fundamentals are different this time, if regional effects are prevalent and if effects differ between housing segments.

A number of historical events and policy regimes such as the real estate and banking crisis as well as housing construction subsidies in the 1990s, Basel I and Basel II, the introduction of free labour movement with the European Union or different monetary policy environments might have changed the interplay of fundamentals and house prices over time. Furthermore, the price developments of single family homes, owner-occupied apartments as well as rented apartments differed quite substantially in the last decades. The tendency of institutional investors to invest in apartment buildings rather than single family houses and the objective to dampen urban sprawl might lead to a different reaction of housing market segments to fundamentals. Finally, spatial planning is implemented on a regional level and house prices differ substantially across Swiss regions, while the monetary conditions are set on a national level. Therefore, the house price dynamics could be heterogeneous across Switzerland.

To assess the effects of different shocks on the development of house prices we employ time-varying coefficients vectorautoregressions (TVC-BVAR), regional BVARs and look at different housing segments. We investigate the price effects of innovations in housing market fundamentals such as financing $\&$ business cycle conditions and housing demand $\&$ supply. We study if the effects of these fundamentals change over time, highlight regional effects and discuss heterogeneous effects for different housing segments.

Studies on causal effects for house prices in Switzerland so far do not utilize time-varying coefficients, thereby ignoring the possibility that parameters changed over the last decades. To capture changes in correlations and parameters we employ time-varying methods. The time period considered ranges from 1982 to 2013. Structural breaks during these three decades are to be expected. These structural changes can affect the assumption of constant cyclical and monetary circumstances. Time-varying parameters absorb these structural breaks, leading to cyclical and monetary circumstances being specific for each point in time. Time-varying methods have the advantage that they can utilize the full data-set, 
if certain sub-periods are of interest. Such subperiods are the decade prior to the Swiss real estate crisis, the decade after the crisis until the financial crisis, and the years since then. ${ }^{1}$

Furthermore, the period after the 2008/2009 financial crisis has not been studied so far. This period has been characterized by a very low interest regime and strong population growth, accompanied by strongly rising house prices in Switzerland, which led to fears about a real estate bubble building up.

Heterogeneity in housing markets might be prevalent if some sub-segments show a more pronounced price development compared to the overall market. Therefore, we explicitly investigate the booming segment of self-owned apartments and condominiums with the overall market.

The development of house prices and fundamentals varies across different regions. For instance, Zurich and Lake Geneva are regions with the strongest house price increases in the last decade. To analyze the interaction of fundamentals and house prices, we apply regional BVAR for eight Swiss regions defined by Wüest \& Partner using data from 1997-2013 and compare them to the national benchmark.

The causal shocks to be studied are unanticipated shocks to the match of housing demand and supply, to mortgage financing conditions (i. e. user costs of housing $)^{2}$, to house price developments and to economic growth. By explicitly focusing on the interplay of housing supply and demand we incorporate features of stock-flow models ${ }^{3}$ into an endogenous vectorautoregressive setup. The difference between population growth and housing stock growth is taken as an indicator for excessive demand or oversupply for housing. It is of interest to use

1 House prices have been rising in Switzerland since the late 1990s. Prior to the recent increase in house prices Switzerland faced a real estate crisis in the 1990s. Before the 1990's real estate crisis the Swiss housing market was experiencing a boom throughout the 1980s.

2 Нотт and Monnin (2008) study how long Swiss real estate prices deviate from their fundamental values. Fundamental values are determined by a rent (i. e. housing cost and return) and a supply/demand model as a function of household income and construction.

3 Investigating Swiss construction and housing markets, STEINER (2010), employing a stockflow framework showed, that a mismatch between desired level of residential capital stock and existing residential capital stock can diverge for some years. Therefore, imbalances have to be adjusted via prices, a surplus in housing leads to falling house prices, a housing shortage leads to rising house prices. Switzerland displays one of the most inelastic short run housing supply curves worldwide. This means that shifts in demand are almost exclusively traduced into changes in residential prices. STEINER (2010) finds, that house prices are an important determinant for the evolution of residential investment, as well as cost shifting variables such as construction costs and mortgage rates. Her results show, that one third of the mismatch between existing and desired residential capital stock will be corrected in the following year. 
excessive housing supply (or excessive housing demand) to explain house price developments. Large immigration flows which lead to high population growth themselves might have only a minor effect on house prices if supply is enlarged simultaneously. Only if a mismatch between the development of housing supply and housing demand exists, shortages (or excessive supply vice versa) might lead to substantial house price movements.

Some, yet time-invariant analyses highlight the endogenous nature of influencing factors and residential prices studying Switzerland. ${ }^{4}$ Using vectorautoregressions on a sample ranging from 1987-2008, Berlemann and Freese (2013) find that positive interest rate shocks have adverse effects on house and condominium prices. They provide a nice overview of the Swiss real estate market. In contrast to their approach we include the interplay between housing demand and housing supply and investigate changes over time to accommodate for different monetary, demographic and regulatory regimes. BOROWIECKI (2009) also studied Swiss construction in the long run. He used annual observations for 17 years. The author finds that house price growth and construction activity react to changes in population and to construction prices, GDP is mentioned to have no effect. House price shocks have no long-term impact on housing supply and vice-versa. Alas, given the short horizon, the confidence intervals for his impulse responses are very wide. BASTEN and КосH (2015) estimate the causal effect of house prices on mortgage demand and supply using micro data from 2008-2013. They find that a $1 \%$ increase of house prices lead to an increase of the mortgage volume by $0.52 \%$, which is primarily driven by mortgage demand. This effect has become stronger over time. Degen and Fischer (2010) have studied

4 Data on Swiss house prices has been included in a number of panel VAR studies. Using data for 1971-2006 including Switzerland Goodhart and Hofmann (2008) as well as AssenMACHER and GERLACH (2008) find a persistent effect of an interest rate shock on house prices, even ten years after the shock. Furthermore, they find a substantial response of house prices to a shock in GDP, which only loses significance ten years after the shock. GoodHART and Hofmann (2008) find a relevant influence of a GDP shock on house prices in general, based on their 17 countries sample from 1971-2006. controlling house price booms, GDP growth does not matter in normal times. On average they also report a significant influence of an interest rate shock on house prices, which also appears to be persistent. Impulse responses depict the country independent average effect, using country fixed effects. It is difficult to infer results for single countries using Panel VARs, homogeneity assumptions of results would be required. As TSATSARONIS and ZHU (2004) show, there is significant variation across countries in both business practices and the regulatory framework for mortgage finance, which influences mortgage rates and thereby user costs of housing. Excess liquidity and the effects on house prices including Swiss data in a global VAR has also been studied by BELKE and OrTh (2007). 
the effect of immigration on Swiss house prices using immigration flows for 85 districts from 2001-2006, finding an effect of $2.7 \%$. Further investigations on Swiss housing market have been conducted by Bourassa, Hoesli, and ScogNAMigLio (2010) and Brown and Guin (2013).

Our analysis shows that fundamentals affect house prices significantly. Changes in the match between housing demand and supply explain with 50\% the most of house price variations. Mortgage rates have a stronger time-varying effect than changes in supply and demand. However, by looking at house prices in general, important dynamics are hidden. The time-varying effect is stronger if we focus on owner-occupied apartment prices. The response of apartment prices to mortgage rate shocks weakened after the 1990s real estate crisis and increased in size again during the recent house price boom. We find evidence for regional heterogeneity, especially for the regions Zurich and Lake Geneva.

The remainder is structured as follows: First an outline of the institutional background of the Swiss housing sector in the past decades as well as a motivation for the time-varying and heterogeneous nature of the Swiss house prices is given. The description of the data used is followed by a short introduction into timevarying VARs. The results of the TVC-BVAR will be displayed and described, followed by a discussion of different housing market segments and the presentation of the regional BVAR estimation. The article concludes with a summary of results and findings.

\section{Institutional Background}

Swiss house prices exhibited large swings in the past decades (Figure 1). The real estate boom in the 1980s caused tremendously rising house prices with annual growth rates of more than $10 \%$. The bust followed in the early 1990s with the real estate crisis. It took about ten years for the house prices to recover. Since 2007, they are growing fast again leading the Swiss National Bank to closely monitor imbalances in the real estate market to avoid the experience from the 1990 s.

There are remarkable differences in the price developments of housing segments in the 1990s and today. During the real estate bubble, the price development of all three house segments was very similar until 1990. Afterwards, the price of rented apartments continued to rise strongly for several years while owner-occupied apartment and single family home prices decreased already. In contrast, owner-occupied apartments experienced a stronger price development since 2000 compared to the other two price indices. 
Figure 1: Swiss House Prices

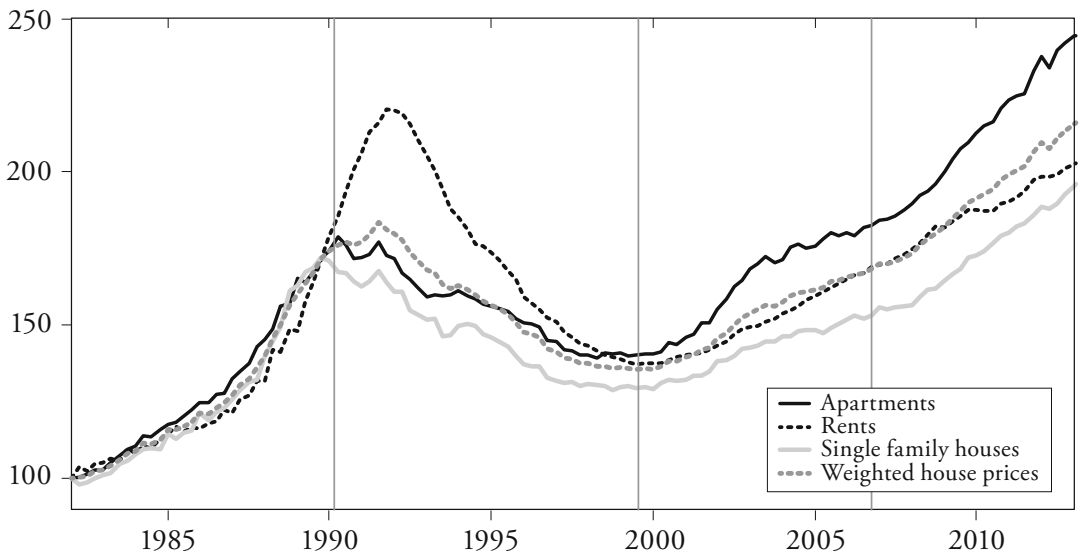

Notes: The figure displays the quarterly development of prices of single-family houses, owner-occupied apartments and rented apartments from Q1 1982 to Q4 2013 (undeflated). The y-axis displays index values indexed to Q1 1982. The continuous light black line displays owner-occupied apartment prices. The grey dotted line depicts prices of rented apartments. The continuous light grey line illustrates single-family house prices while the dashed grey line represents a weighted house price index (37.5\% single family houses, $37.5 \%$ owner-occupied apartments, $25 \%$ rented apartments). The vertical lines mark the four sub-periods discussed in chapter 2 .

The Swiss housing market was marked by a number of structural changes which might have not only contributed to these house price cycles, but have triggered parameter changes regarding the variables of investigation. These can be divided into policies, which directly aim at influencing the housing sector and policies and economic developments which have side-effects.

5 A number of policy interventions currently aim at influencing factors of a housing boom: Macroprudential measures addressing mortgages aim to foster resilience of the banking sector and of borrowers to real estate shocks. Such interventions might also influence mortgage rates. As part of banks' self-regulation, mortgage holders need to have at least $10 \%$ of the mortgage value as capital (without pension fund capital) since 2012. Furthermore, the mortgage needs to be amortised by two thirds within 20 years, which was again lowered to 15 years in 2014 . A valuation at the lower of costs or market prices was also introduced. The Swiss National Bank activated the countercyclical capital buffer of $1 \%$ in 2013 and increased it to $2 \%$ a year later. All these measures influence mortgage lending. The prohibition of vacation home construction in tourist regions with a share of more than $20 \%$ second homes alongside various land-use planning acts aim to reduce new construction outside settled areas since 2013. 
Different regulatory settings for mortgage loans such as Basel I and Basel II alongside with the introduction of sophisticated risk management systems might have influenced the mortgage lending behavior of banks. Additionally, the introduction of real estate transfer taxes in 1992 as well as housing construction subsidies by the federal government in 1993 might have influenced the interplay of housing demand and supply, mortgage rates and house prices.

With the obligation to deposit into pension funds in 1985, suddenly large amounts of money had to be invested by institutional investors driving up asset and house prices. The real estate crisis and the regional banking crash in the early 1990s influenced the housing sector dramatically. Also recently, institutional investors invested in the Swiss real estate market on the search for yield. Institutional investors are generally more likely to invest into multifamily houses rather than single family homes. Hence, their behaviour might have a bigger impact on rented apartment prices. ${ }^{6}$

The current low interest rate environment (with even negative interest rates) differs from the interest rate regimes experienced in the 1980s and 1990s. At the same time mortgage rates reached all-time lows in consequence to a lowering of LIBOR target rates by the Swiss National Bank into negative territories in December 2014. ${ }^{7}$ Mortgage rates dropped to historically low rates of $2.7 \%$ (December 2013). ${ }^{8}$

Population growth, an important driver of housing demand in Switzerland, varied tremendously in the last decades and across Swiss regions. While net migration in the mid-1990s basically was zero, the picture looks different in the 2000s. As a consequence to the full introduction of the free labour movement agreement with the European Union immigration numbers have risen strongly since 2007 (treaty signed 1999, first step 2002, full liberalization 2007). The adopted mass migration initiative by the Swiss electorate foresees immigration quotas from 2017 onwards, which will limit immigration flows and the demand for housing.

An important driver of house price developments on the regional level is the Swiss spatial planning law. Since 1969, the federal state is responsible to set the

6 According to the Swiss pension fund statistic published by SFSO, the Swiss pension funds' direct investments into Swiss real estate rose form CHF 72.4 billion in 2005 to CHF 113.4 billion in 2013. Therefore, the share of the Swiss real estate investment of the total assets increased from $13.3 \%$ to $15.7 \%$ over the same time frame (see i. e. Credit Suisse (2015)).

7 The recent repeal of the Swiss Franc/Euro exchange rate lower bound on January 15th 2015 came together with a renewed lowering of the interest band.

8 Several months after the introduction of the negative interest rates, mortgage rates rose because Swiss banks had higher refinancing costs, which they passed on to mortgage holders. 
guiding legislation and to coordinate the canton's spatial planning activities. The development and implementation of spatial planning acts are established on a cantonal basis, while the cantons can delegate tasks to municipalities. This set-up leads to very different spatial planning rules across Switzerland. For instance, the cantons of Geneva and Basel are very restrictive in handing on responsibilities to the communal level, while other cantons delegate extensive tasks (MülLERJeNTSCH and RüHLI, 2010). Furthermore, cantons with larger urban areas such as Geneva, Zurich or Basel are more active and efficient in its urban planning activities while other cantons (particularly small cantons) follow a laissez-faire style. This results in varying availability of building areas which could than feedback to land and house prices (see i. e. building area statistic Switzerland), which adds to the per se heterogeneous structure of Swiss cantons (language, topological differences).

Furthermore, the objective of the spatial planning acts to promote the building of apartment buildings compared to single family houses could affect housing segments differently. In May 2014, a new spatial planning law was implemented which implements new measures to moderate the urban sprawl.

Therefore, these different regimes and policies might lead to different parameters describing the relationships among fundamentals and house prices not only over time, but also across housing segments and regions.

\section{Data}

Data considered in the analysis refer to a mismatch between housing supply and demand, mortgage rates, GDP growth as well as house prices.

The match between housing demand (population growth) and housing supply (housing stock growth) is measured as the difference between population growth rates and housing stock growth rates. In the following, such a difference between growth rates, which is equal to the change in the population $\&$ housing ratio, will be named population adjusted housing supply growth. Data on population are taken from the Swiss Federal Statistical Office. The population number is the total population by the end of the year.

The housing stock in 1980 has been derived by the vacancy rate and the number of unoccupied apartments in 1980 as provided by the Swiss Federal

9 Vacancy rate, Table je-d-09.02.02.03.01 in Bau- und Wohnungswesen 2012, Swiss Federal Statistical Office, Neuchatel, published 2014. 
Statistical Office. 'The vacancy rate and the number of unoccupied apartments are vacancies in relation to the housing stock of the previous year. Updates of the housing stock are based on net increases of housing stock as published by the Swiss Federal Statistical Office. ${ }^{10}$ Housing stock is taken as Q4 value. Quarterly values for population and housing stock have been interpolated by using a cubic spline. ${ }^{11}$

The interpolated population and housing stock levels are illustrated in Figure 2. Naturally, the population level is higher. Both variables are continuously rising since the beginning of the 1980s. More interestingly, the ratio of the population to housing stock decreased slightly during the period of investigation (Figure 3). ${ }^{12}$ The housing stock grew by $0.8 \%$ to $1.6 \%$. Population growth experienced larger swings and ranges between $0.2 \%$ to $1.4 \%$.

Mortgage rates are median values of variable rates for new mortgages as provided by the Swiss National Bank. ${ }^{13}$ Relative mortgage rate developments (calculated as quarter-over-previous-year-quarter growth rates) have been taken to proxy user costs. Monthly instalment payments directly depend on mortgage rates (see for instance DiPasquale and Wheaton (1994), Steiner (2010) or Hott and Monnin (2008)). If the mortgage rate declines, user costs decline too and housing purchases are more affordable. Another advantage of using mortgage rate changes is the implicit standardization of mortgage rate shocks. Due to the current low interest regime a one standard deviation shock these days is smaller in nominal terms compared to a nominal mortgage rate shock in the 1990s. Using mortgage rate changes helps to argue more in line of "what are the effects of a $10 \%$ increase in mortgage rates on house prices". ${ }^{14}$

10 Annual new construction and refurbishments of apartments, Table je-d-09.02.02.01 in Bauund Wohnungswesen 2012, Swiss Federal Statistical Office, Neuchatel, published 2014.

11 We have chosen this approach rather than using housing stock figures published by the Swiss Federal Statistical Office because of a structural break in the time series. Before 2009, housing stock figures are approximated values. After 2009, the Gebäude- und Wohnungsstatistik publishes more exact figures which leads to a very high growth rate in 2009. We have conducted a robustness check using the two housing stock series by the Swiss Federal Statistical Office. The impulse of house prices on a shock of the population adjusted housing supply growth exhibits a double dip. The time variation of the coefficients remains.

12 There is a trend to smaller households, respectively bigger apartments. The number of people per room is decreasing since the 1970s.

13 Robustness checks have been conducted by using the average mortgage rate of all cantonal banks until 2008 and the mortgage rates of the Bundesamt für Wohnungswesen thereafter. The impulse response functions exhibit a similar pattern.

14 For results using mortgage rates (in levels) please refer to the appendix. 
Figure 2: Swiss Population and Housing Stock Level

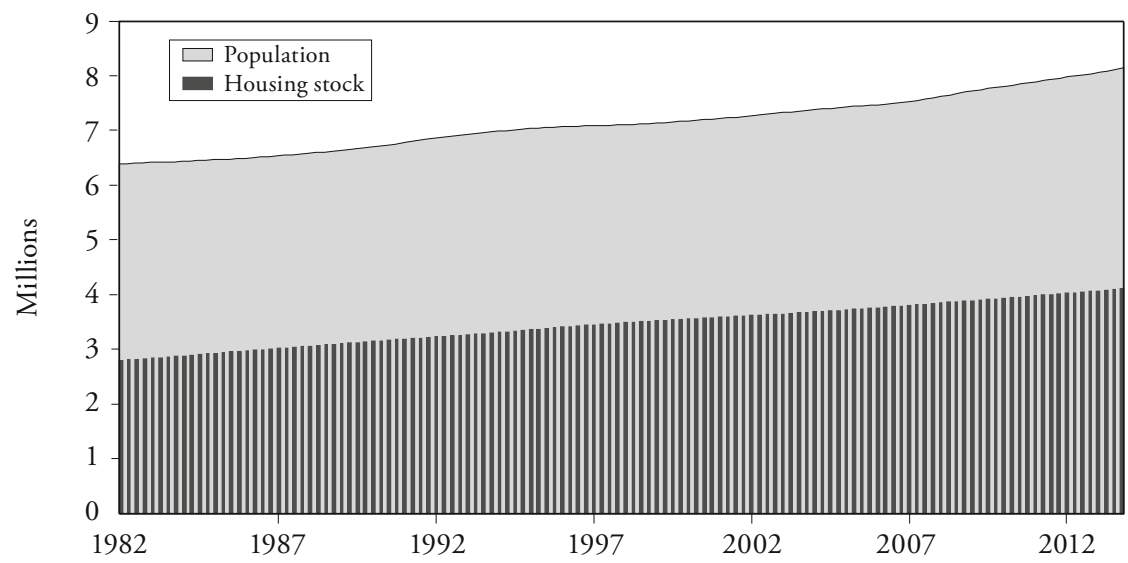

Notes: The figure displays the quarterly development of the Swiss population and the housing stock from Q1 1982 to Q4 2013. The y-axis displays the level in million. The grey area displays the population. The dark grey bars depicts the housing stock.

\section{Figure 3: Swiss Population and Housing Stock Growth}

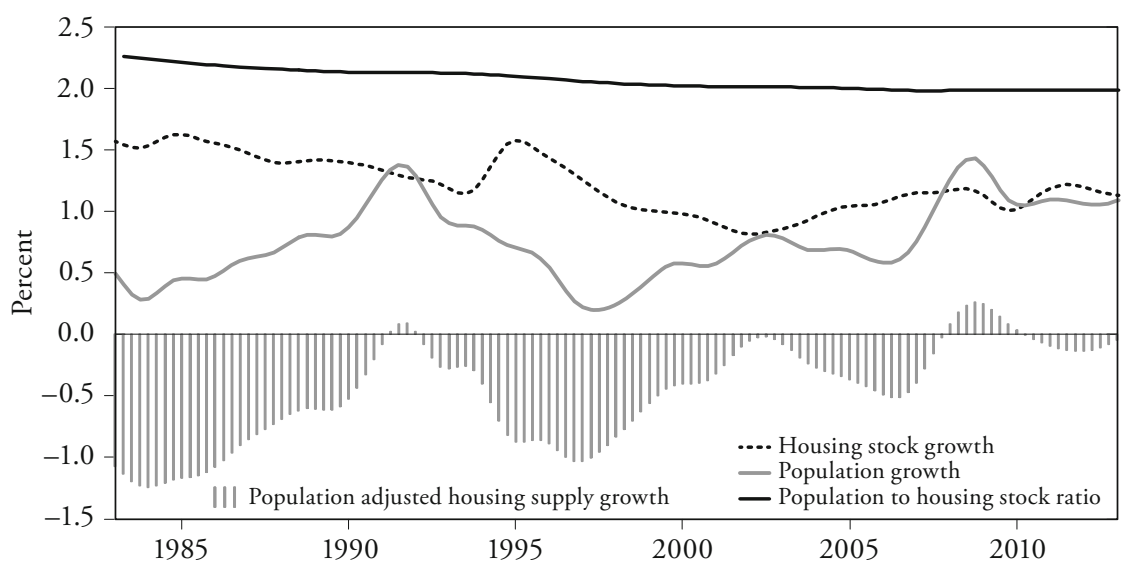

Notes: The figure displays the quarterly development of the ratio of population to housing stock, population growth, housing stock growth as well as the population adjusted housing supply growth from Q1 1983 to Q4 2013. The y-axis displays values in percentage terms. The solid black line illustrates the ratio of population to housing stock. The dotted black line displays housing stock growth. The grey line depicts population growth. The grey bars depict the population adjusted housing supply growth. 
Data on quarterly real GDP is taken from the Swiss Federal Statistical Office and the Swiss Secretariat for Economic Affairs (SECO). GDP is a proxy for the business cycle and household income. As a proxy for house prices a weighted index of the asking price series of single family homes (37.5\%), owner-occupied apartments (37.5\%) and rented apartments $(25 \%)$ as published by Wüest \& Partner has been chosen. We will refer to the weighted house price index as house prices throughout the paper. A second estimation using the asking price index of owner-occupied apartments will be presented (apartment prices) to highlight heterogeneity in housing markets. House and apartment prices have been deflated using CPI, as published by the Swiss Federal Statistical Office. Growth rates for population and housing stock, GDP as well as house and apartment prices are calculated as quarter-over-previous-year-quarter growth rates. The data-set ranges from 1982-2013. Due to the calculation of growth rates the time period considered ranges from 1983 to 2013.

For the regional analysis, we use disaggregated weighted house price data for eight market regions defined by Wüest \& Partner based on MS-regions. Unemployment rates, population and housing stock figures are allocated according to the Wüest \& Partner's region definition. Unemployment rates are used instead of GDP because of disaggregation considerations. Furthermore, GDP figures are only available from 2008 onwards. Data is on a semi-annual basis and ranges from the second half of 1997 until 2013 (limited by the housing stock). With the exception of using unemployment rates (SECO) instead of GDP, variables are defined as before. The mortgage rate change is on a national level since mortgage rate settings are unlikely to differ between regions. Growth rates are calculated as annual growth rates.

The development of house prices, population adjusted housing supply growth, mortgage rate change and GDP growth have undergone strong swings during the last three and a half decades (see Figure 4). By looking at Figure 1 and 4 it can be observed, that house price developments since the early 1980 s can be divided into four subperiods also if inflation developments have been accounted for. Until the end of the 1980s house prices rose strongly, reaching quarter-overprevious-year-quarter growth rates of up to $10 \%$. Starting in the late $1980 \mathrm{~s}$ house prices first started to stagnate and declined strongly until the late 1990s. Reductions in house prices by $10 \%$ in comparison to the previous year's quarter can be observed. In the late 1990s house prices started to recover and grew until the early 2000s. From the early 2000s until 2007 house prices almost stagnated with very low growth rates. Since 2007 house prices rose strongly again, with a declining trend in growth rates at the end of the sample. 
Figure 4: Swiss House Prices, Population Adjusted Housing Supply Growth, Mortgage Rates and GDP Growth over Time

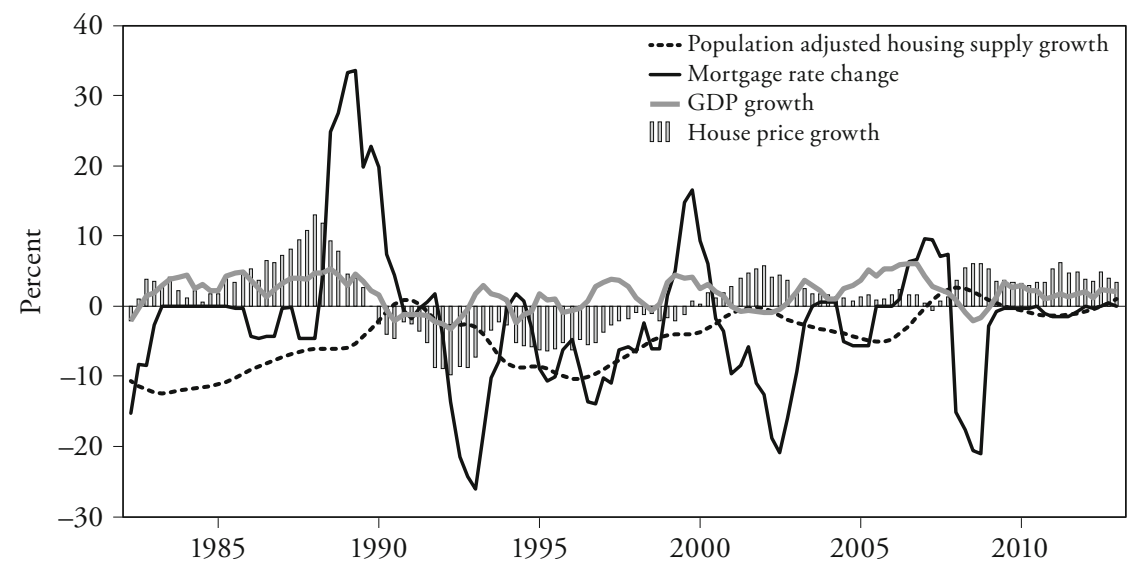

Notes: The figure displays the quarterly development of deflated house price growth, the population adjusted housing supply growth, mortgage rate change and GDP growth from Q1 1983 to Q4 2013. The $y$-axis displays values in percentage terms. Growth rates are depicted in quarter-overprevious-year-quarter rates. The bars show apartment price growth rates. The continuous black line depicts changes in the mortgage rate. The dotted black line displays the difference between population growth and housing stock growth. The grey line represents GDP growth.

Mortgage rates were subject to substantial swings during the sample period. With the change in the monetary regime settings of the Swiss National Bank by the end of the 1980s and in consequence to imported inflation from Germany after the reunification nominal interest rates rose sharply. Consequently, mortgage rates were affected. In relative terms the user costs of housing, i. e. the mortgage rate change, rose by up to $30 \%$ in quarter-over-previous-year-quarter comparison. During the early 1990s, when house prices deteriorated, Switzerland entered a recession and the banking sector experienced financial turmoil. ${ }^{15}$ Interest rates and consequently mortgage rates were lowered again, leading to a reduction in mortgage rate change by up to $25 \%$. Only by the end of the 1990 s mortgage rates rose again, before declining substantially in the wake of the dot.com turmoil. Prior to the financial crisis interest and mortgage rates increased again in

15 A bank run on Spar-und Leihkasse Thun, troubles in cantonal banks Solothurn, Berne and Appenzell Inner Rhode, as well as for Volksbank and several regional banks. 
2006/2007, before decreasing to record low levels - mortgages were available at $2.7 \%$ in December 2013.

In the majority of time periods between 1982 and 2013 the growth rate of housing stock exceeded the population growth rate: new construction also incorporates new vacation homes. At the same time, the number of persons living in each apartment has declined steadily during the last decades. The dynamics of the series show the strong increase in population during the 1980s, being caused by a substantial migration inflow. During the early 1990 s immigration numbers dwindled, while housing production - being especially subsidized by federal government in 1993 - reached a peak in 1994. Declining numbers of immigrants with expanding housing stock lead to an oversupply in housing by the mid-1990s. With the construction industry facing headwind and lowering production in the second half of the 1990s, the economy recovering and a rising number of immigrants the oversupply was reduced. During the first half of the 2000s housing stock expansion was again stronger than population growth, while since 2007 the year of the full-fledged implementation of free labour movement - population growth rates exceeded housing stock expansion rates.

Turning to GDP, the Swiss economy was growing strongly in the 1980s after the second oil crisis. In the early 1990s the Swiss economy went into a recession and stagnated until 1997. During the dot.com boom years the economy expanded again while experiencing zero growth in 2002. Up until the onset of the 20072009 financial crisis the Swiss economy was performing strongly, followed by a decline during the financial crisis and moderate growth rates afterwards.

\section{Method}

\subsection{BVAR}

Bayesian vector autoregressive models treat variables of an estimation system as endogenous, meaning that all changes of individual variables affect the entire system and are at the same time endogenously affected by the follow-up reactions. Let $\mathrm{y}_{t}$ be a $M \times 1$ vector containing $M$ variables at time $t$ which is part of a reduced form VAR representation ${ }^{16}$

$$
\mathbf{y}_{t}=\mathbf{\alpha}_{0}+\mathbf{\alpha}_{1} \mathbf{y}_{t-1}+\mathbf{\alpha}_{2} \mathbf{y}_{t-2}+\cdots+\boldsymbol{\alpha}_{p} \mathbf{y}_{t-p}+\varepsilon_{t}
$$

16 The following short introduction into BVARs is based on Koop and Korobilis (2010). 
where $\boldsymbol{\alpha}_{0}$ is a $M \times 1$ vector of intercepts, $\boldsymbol{\alpha}_{i}$, for $i=1, \ldots, p$ are $M \times M$ matrices of coefficients with lag structure $p$ and $\varepsilon_{t}$ is a $M \times 1$ Gaussian white noise process with zero mean and covariance $\Sigma$.

Rewriting yields:

$$
\mathbf{y}_{t}=\mathbf{X}_{t}^{\prime} \boldsymbol{\theta}+\varepsilon_{t}
$$

where $\mathbf{X}_{t}^{\prime}=\mathbf{I}_{M} \otimes \mathbf{x}_{t}^{\prime}$ is a $M \times(M p+1) M$ matrix, with $\mathbf{I}_{M}$ representing a $M \times M$ identity matrix and $\mathbf{x}_{\mathrm{t}}^{\prime}=\left[1, \mathbf{y}_{t-1}^{\prime}, \mathbf{y}_{t-p}^{\prime}\right] . \boldsymbol{\theta}=\operatorname{vec}\left(\boldsymbol{\alpha}^{\prime}\right)$ collects the (time-constant) VAR coefficients, with $\boldsymbol{\alpha}^{\prime}=\left(\boldsymbol{\alpha}_{0} \boldsymbol{\alpha}_{1} \boldsymbol{\alpha}_{2} \ldots \boldsymbol{\alpha}_{p}\right)^{\prime}$.

Independent Normal-Wishart-priors are used as priors. They were chosen as diffuse as possible in order for the variance to provide a sufficient flexibility. The lag length is chosen to be two by using quarterly data and one in the regional analysis by using semi-annual data. ${ }^{17} \mathrm{~A}$ Gibbs-sampler is used to draw from the Normal and Wishart distribution to calculate the median parameter values.

\subsection{TVC-BVAR}

The estimation of time-varying parameters allows an investigation of time-dependent causal effects. Considering periods individually, it becomes possible to detect changes in the responses to economic shocks over time.

Let $\mathbf{y}_{t}$ be a $M \times 1$ vector containing $M$ variables at time $t$ which is part of a reduced form VAR representation ${ }^{18}$

$$
\mathbf{y}_{t}=\boldsymbol{\alpha}_{0, t}+\boldsymbol{\alpha}_{1, t} \mathbf{y}_{t-1}+\boldsymbol{\alpha}_{2, t} \mathbf{y}_{t-2}+\ldots+\boldsymbol{\alpha}_{p, t} \mathbf{y}_{t-p}+\varepsilon_{t}
$$

where $\boldsymbol{\alpha}_{0, t}$ is a $M \times 1$ vector of time-varying intercepts, $\boldsymbol{\alpha}_{i, t}$, for $i=1, \ldots, p$ are $M \times M$ matrices of time-varying coefficients with lag structure $p$ and $\varepsilon_{t}$ is a $M \times 1$ Gaussian white noise process with zero mean and covariance $\Sigma$.

17 Further parameter specification: The number of draws is 100000 . Burn-in: Only the last 20000 draw are used for the analysis.

18 The following short introduction into TVC-BVARs is based on Hamilton (1994), DeL Negro and Schorfheide (2011), Gambetti (2005), Koop and Korobilis (2010) and Kim and Nelson (2003). 
Rewriting the model in state space ${ }^{19}$ form and vectorizing expressions:

Measurement equation: $\quad \mathbf{y}_{t}=\mathrm{X}_{t}^{\prime} \boldsymbol{\theta}_{t}+\varepsilon_{t}$

State equation:

$$
\boldsymbol{\theta}_{t+1}=\boldsymbol{\theta}_{t}+\mathbf{u}_{t+1}
$$

where $\mathbf{X}_{t}^{\prime}=\mathbf{I}_{M} \otimes \mathbf{x}_{t}^{\prime}$ is a $M \times(M p+1) M$ matrix, with $\mathbf{I}_{M}$ representing a $M \times M$ identity matrix and $\mathbf{x}_{t}^{\prime}=\left[1, \mathbf{y}_{t-1}^{\prime}, \mathbf{y}_{t-p}^{\prime}\right]$. States $\boldsymbol{\theta}_{t}$ are assumed to follow a random walk and are described by $\boldsymbol{\theta}_{t}=\operatorname{vec}\left(\boldsymbol{\alpha}_{t}^{\prime}\right) \cdot \boldsymbol{u}_{t}$ collects the $((M p+1) M \times 1)$ Gaussian white noise process independent of $\varepsilon_{t}$ with zero mean and covariance matrix $\Omega$.

Time-varying parameters can be estimated using the Kalman filter and Kalman smoother. The estimation takes place using Bayesian estimation procedures. ${ }^{20}$

Carter and Kohn (1994) have demonstrated how to use the Gibbs-sampler to infer $\boldsymbol{\Sigma}$ and $Q$ from the posterior of $\boldsymbol{\beta}_{t}$, given the unknown but fixed parameters. The Gibbs-sampler is applied to deduce sequences from conditional distributions by the use of parameters calculated with the Kalman filter. ${ }^{21}$ This allows for an approximate calculation of a common probability distribution and eventually a determination of average (or median) parameter values.

19 The specific measurement and state equations are a special case of a general space state representation:

$$
\mathbf{y}_{t}=\mathrm{W}_{t} \boldsymbol{\delta}+\mathrm{Z}_{t} \boldsymbol{\theta}_{t}+\varepsilon_{t}
$$

and

$$
\boldsymbol{\theta}_{t+1}=\mathrm{T}_{t} \boldsymbol{\theta}_{t}+\mathbf{u}_{t}
$$

whereby $\mathrm{W}_{t}$ represents a matrix with $M \times 1$ exogenous variables and $\delta$ the corresponding parameter vector. The matrix $\mathrm{T}$ transforms the latently unknown parameters $\boldsymbol{\theta}_{t}$ into their next state $\boldsymbol{\theta}_{t+1}$. T is an identity matrix in this application. The error terms of the state equation are by definition normally distributed with $\mathbf{u}_{t} \sim N\left(0, \mathbf{Q}_{t}\right)$, where $\varepsilon_{t}$ and $\mathbf{u}_{t}$ are independent from each other over all points of time. Variance-covariances $(\Sigma, \Omega)$ are considered time-invariant.

20 Alternative maximum-likelihood-estimation procedures require too much computing time compared to a repeated exertion of the filter to optimize the unknown parameters.

21 Further parametric specifications: Lag-length is set to 2, as an inclusion of lag length $>2$ would reduce the degrees of freedom too substantially. The number of draws is 100000 . Burn-in: Only the last 20000 draws are used for the analysis (the first 80000 are discarded), of which only every tenth draw is saved and evaluated. Rejection Sampling: If the eigenvalue of the parameter-matrix leads to an explosive behavior of the impulse response function, the entire draw will be rejected. Convergence has been checked by plotting the trace of parameter values. 
Independent Normal-Wishart-priors are used as priors. They were chosen as diffuse as possible in the state equation in order for the variance to provide a sufficient flexibility of the state parameters. The entire sample was used as training sample because of the relative small number of observations. Starting values where retrieved by using OLS estimates.

\subsection{Identification}

Because of the endogeneity of variables it is difficult to interpret the parameters directly. An interpretation is usually done using a vector autoregressive moving average representation (VARMA), which allows for the derivation of impulse response functions. They represent the reactions of specific variables to an exogenous, orthogonal shock (innovation). This shock is by definition independent from other shocks. To ensure this independence, error terms and therefore the variance-covariance matrix have to be rewritten in a way that innovations do not correlate with other innovations. This is often done by decomposing the variance-covariance matrix, for instance with a Cholesky decomposition. Doing so, contemporaneous zero restrictions are set.

When applying a Cholesky decomposition for identification, impulse response functions may depend on the ordering of endogenous variables. Ordering in the BVAR and TVC-BVAR setup, from not being contemporaneously being affected by covariates to being contemporaneously being affected by all covariates:

1. Population adjusted housing supply growth

2. Mortgage rate change

3. GDP growth (respectively unemployment rate)

4. House prices

The population adjusted housing supply growth is contemporaneously in quarter $t=0$ assumed to not be affected by innovations in the other variables. Migration decisions are contemporaneously usually not affected by innovations in the other variables. So is the housing stock - usually the construction process takes longer than a quarter, almost finished apartments will be finished, irrespective of any other economic shock.

Mortgage rates depend on interest rate target bands and banks' policies. Monetary authorities are assumed to contemporaneously not react to house price or GDP developments (nevertheless they might react later on). Changing the placement of mortgage rate change does not affect the results. 
GDP growth (respectively the unemployment rate) is assumed to be contemporaneously affected by population and housing stock growth as well as by interest rates. House prices are assumed to not influence GDP growth contemporaneously. House prices react to all innovations of other variables contemporaneously.

\section{Results}

We will first present the results of the TVC-BVAR. While focusing on the aggregate house prices, important time-varying dynamics effects of sub-components and regions are hidden. The time-varying effect is stronger if we focus on owneroccupied apartment prices. Second, regional heterogeneity is present and is highlighted by the regional BVARs' results.

\subsection{Time Variation}

The stock flow literature (see DiPAsquale and Wheaton (1994)) ascribes a strong influence to a mismatch between supply and demand for housing on residential property prices. If housing supply expands more than the demand for new housing, an oversupply in housing might be the consequence and prices might go down. If population growth expands more than housing supply, an undersupply in housing might be the consequence and house prices might rise. Therefore it depends which of the two influencing factors expands more than the other, or if they expand at the same relative rate. Over- and undersupply will be approximated by the difference in growth rates between population growth and construction growth (i. e. population adjusted housing supply growth).

As can be seen in Figure 5 substantial responses of house prices to a shock on population adjusted housing supply growth can be observed. As a base case, we first present the results of a Bayesian VAR without time-varying parameters using the same prior, lags and Cholesky ordering. The BVAR IRFs are displayed as grey dotted lines. House prices respond as expected negatively to a negative shock of population adjusted housing stock growth. The peak effect to a negative shock is $-1.5 \%$ in median house price growth rates 1.5 years after the shock. The response is hump-shaped. Turning to the results of the TVC-BVAR shows, that the shock is more persistent in the 1980s, since the effects are zero again 5 years after the shock. Since the 1990s the shock leaves the system after 4 years.

The fraction of the forecast error variance explained by the population adjusted housing supply growth is almost $50 \%$ in the 1980s and declines to about $45 \%$ in the most recent years (see Figure 6). The results are in line with the findings 
Figure 5: Response of House Prices to a Shock on Population Adjusted Housing Supply Growth
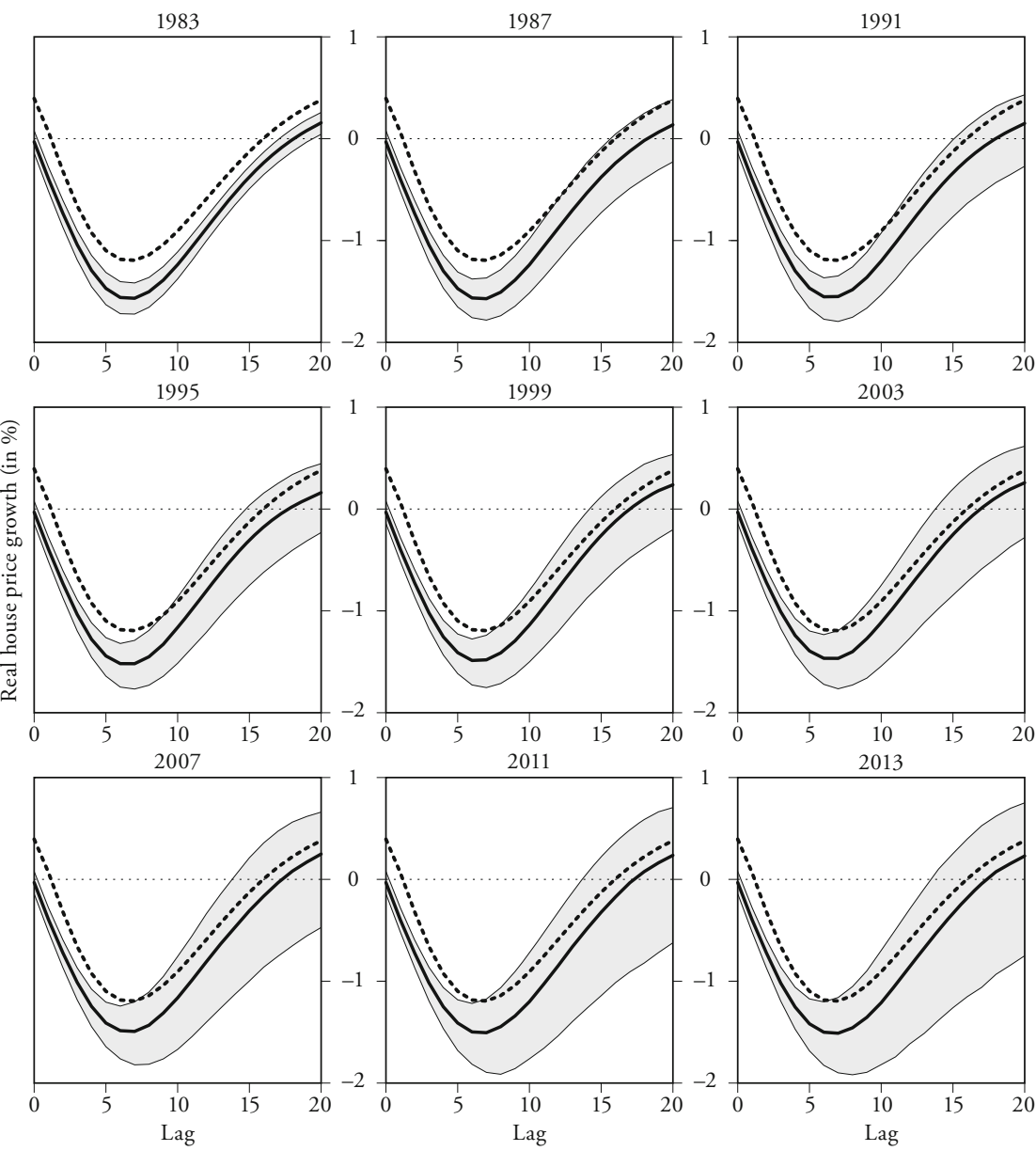

Notes: This figure represents the impulse response functions of the reaction of house prices to a negative shock on population adjusted housing supply growth. Such a shock could be caused by an unanticipated decline in population growth or by an unanticipated increase in construction of new apartments. The magnitude of the shock is set to one standard deviation $(0.57 \%)$. The $\mathrm{x}$-axis depicts the lags as measured in quarters. The ordinate displays the responses in percentage points. The results are based on the previously described use of a TVC-BVAR. Each plot refers to a specific observation point. For each point in time results a different impulse response function because of the time-varying estimation. The continuous line represents the median and the grey surface the error bands up to one standard deviation of the TVC-BVAR estimation. The grey dotted lines are the impulse response function after estimating a standard BVAR described in the text. 


\section{Figure 6: Variance Decomposition of House Prices}

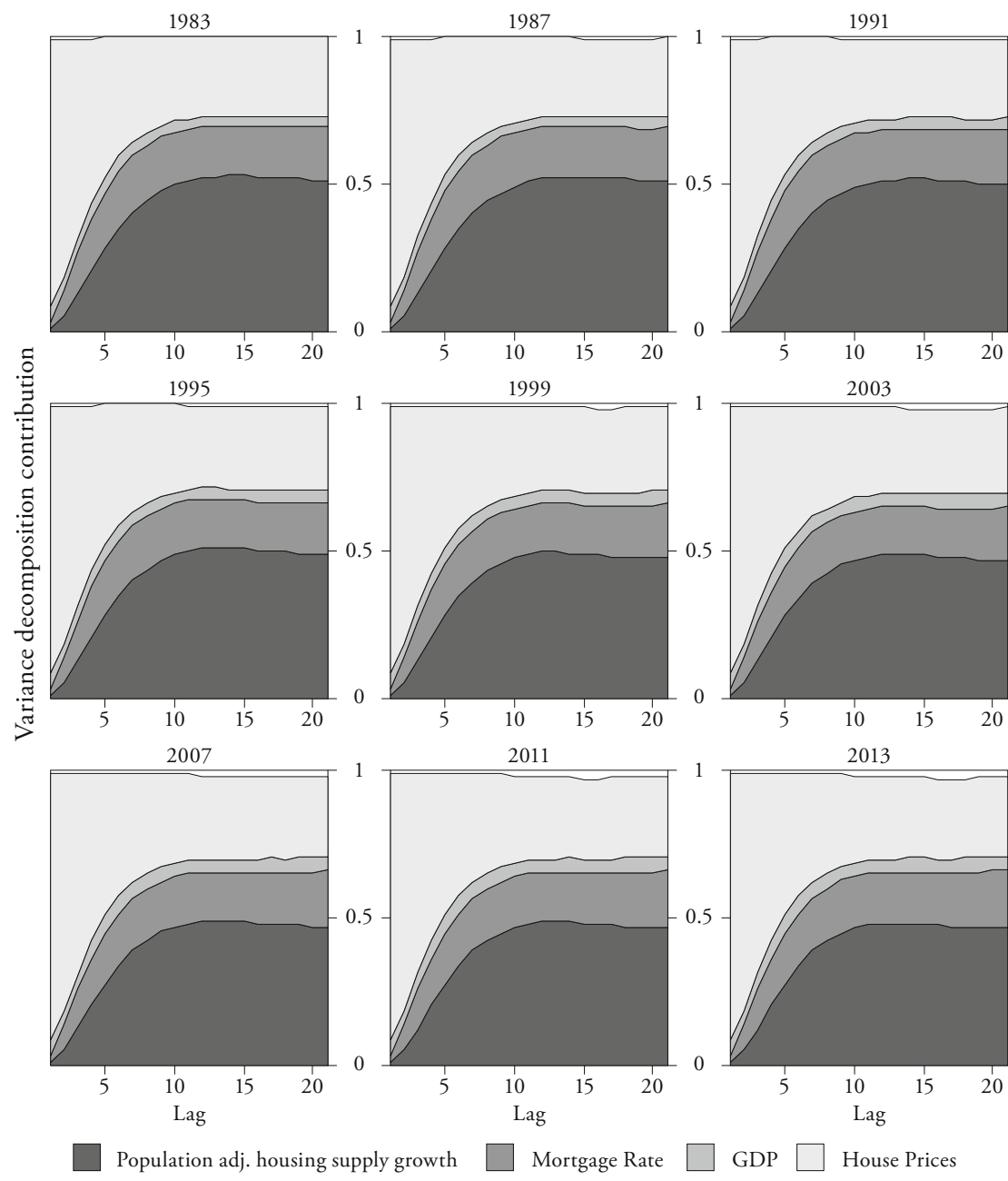

Notes: This figure represents the forecast error variance decomposition of the reaction of house prices to negative shocks on population adjusted housing supply growth, relative mortgage rate developments and GDP growth. The magnitude of the shock is set to one standard deviation. The $\mathrm{x}$-axis depicts the lags as measured in quarters. The ordinate displays the explained forecast error variance in percentage points. The results are based on the previously described use of a TVC-BVAR. Each plot refers to a specific observation point. For each point in time results a different variance decomposition because of the time-varying estimation. Stacked areas depict median responses. 
Figure 7: Effect (after 8 quarters) of House Price Responses to a Shock on Population Adjusted Housing Supply Growth

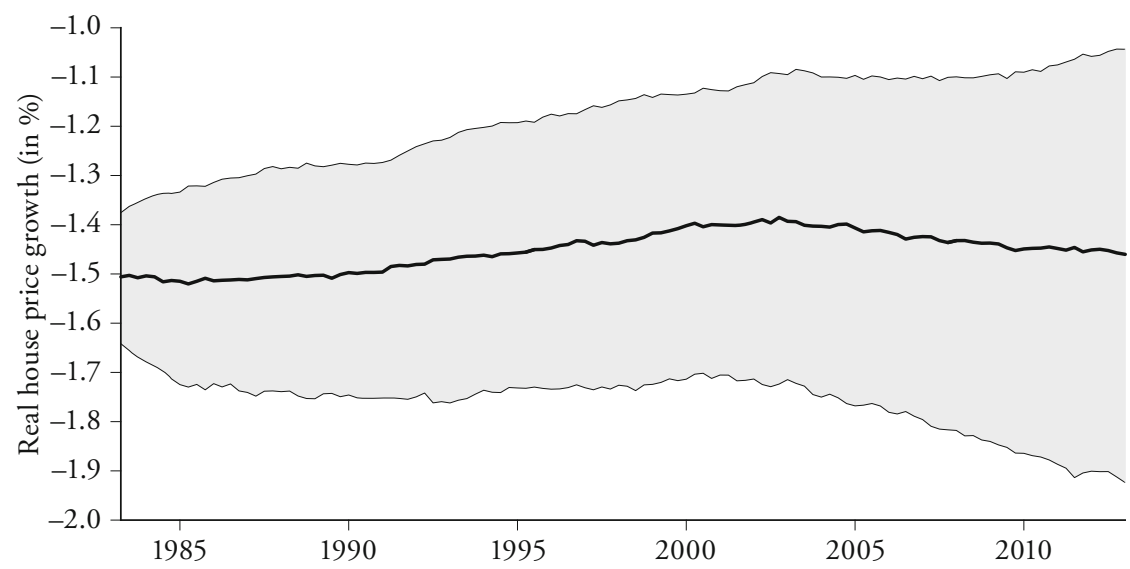

Notes: This figure represents the movement of impulse responses over time, measured 8 quarters after the shock of house prices to a negative shock on population adjusted housing supply growth. The magnitude of the shock is set to one standard deviation $(0.57 \%)$. The $\mathrm{x}$-axis depicts the lags as in quarters. The ordinate displays the responses in percentage points. The results are based on the previously described use of a TVC-BVAR. The continuous line represents the median and the grey surface the error bands up to one standard deviation.

by Degen and Fischer (2010), which report substantial effects of house price increases in reaction to an increase in immigration. They find that two-thirds of price increases can be explained by immigration, using vacancy rates as control. The time variation of the response of house prices to innovations of the population adjusted housing supply growth is illustrated in Figure 7. It shows the median response after 8 quarters over the whole period under investigation. The response of house prices is the highest in the 1980 s with about $-1.5 \%$. The effect became smaller until the year 2002 with about $-1.4 \%$ and is somewhat stronger in recent years. Hence, for the response of house prices to a shock on population adjusted housing supply growth we do not observe strong time-variant effects.

Figure 8 displays the effect of a shock of the mortgage rate change with the size of one standard deviation on house prices. House prices respond positively to a negative shock on mortgage rate change. The peak effect is about $1.1 \%$ (standard BVAR). Mortgage rate effects are persistent in the short run. While the impulse responses decline from their peak effects (which are observed after one 
Figure 8: Response of House Prices to a Shock on the Mortgage Rate Change (i. e. User Costs)
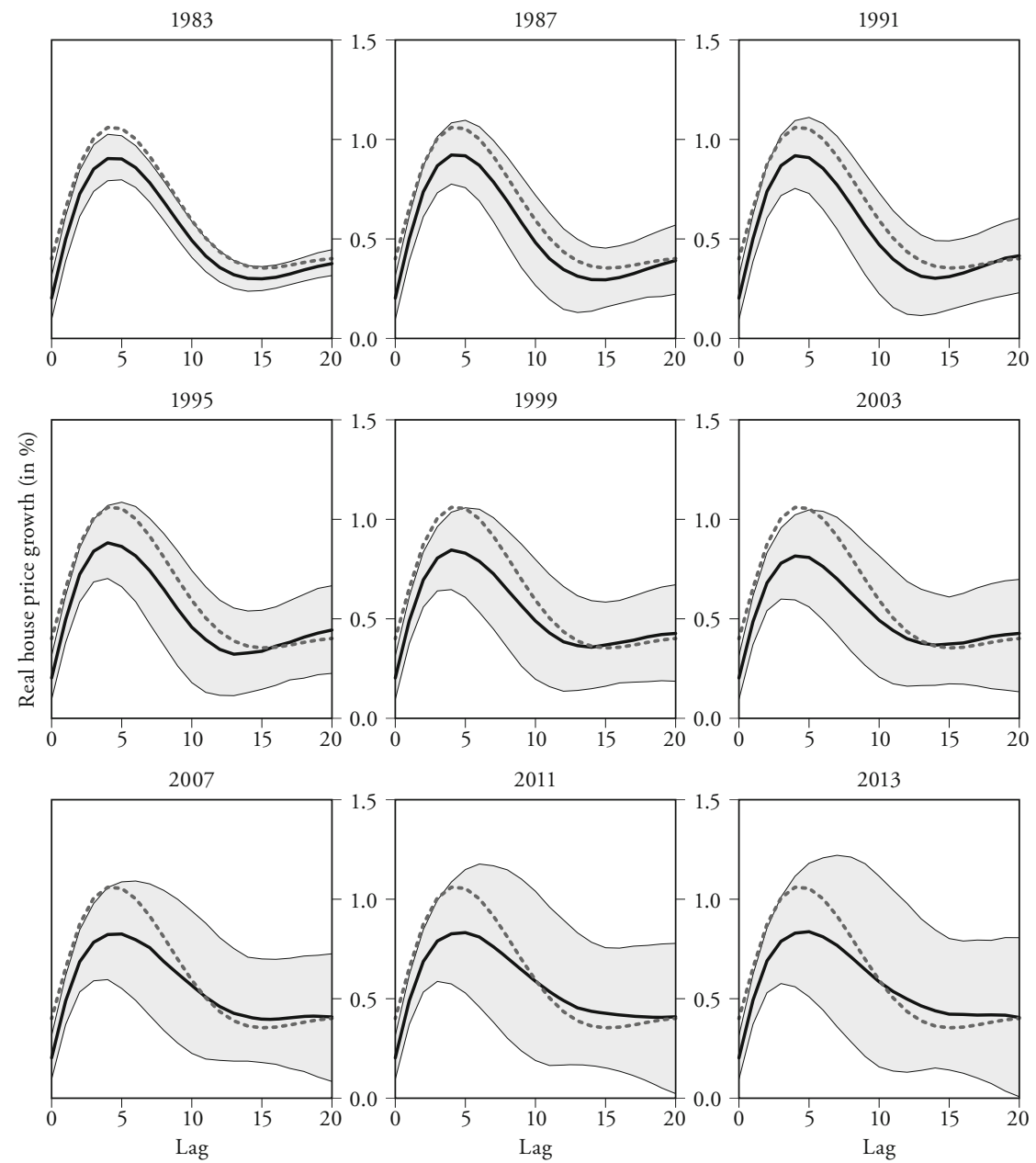

Notes: This figure represents the impulse response functions of the reaction of house prices to a negative shock on the mortgage rate change (i. e. user costs). Such a shock could be caused by an unanticipated decline in the change in the mortgage rate. The magnitude of the shock is set to one standard deviation (4.8\%). The $\mathrm{x}$-axis depicts the lags as in quarters. The ordinate displays the responses in percentage points. The results are based on the previously described use of a TVCBVAR. Each plot refers to a specific observation point. For each point in time results a different impulse response function because of the time-varying estimation. The continuous line represents the median and the grey surfaces the error bands up to one standard deviation. The grey dotted lines are the impulse response function after estimating a standard BVAR described in the text. 
Figure 9: Peak Effect (after 5 Quarters) of House Price Responses to a Shock on the Mortgage Rate Change (i.e. User Costs)

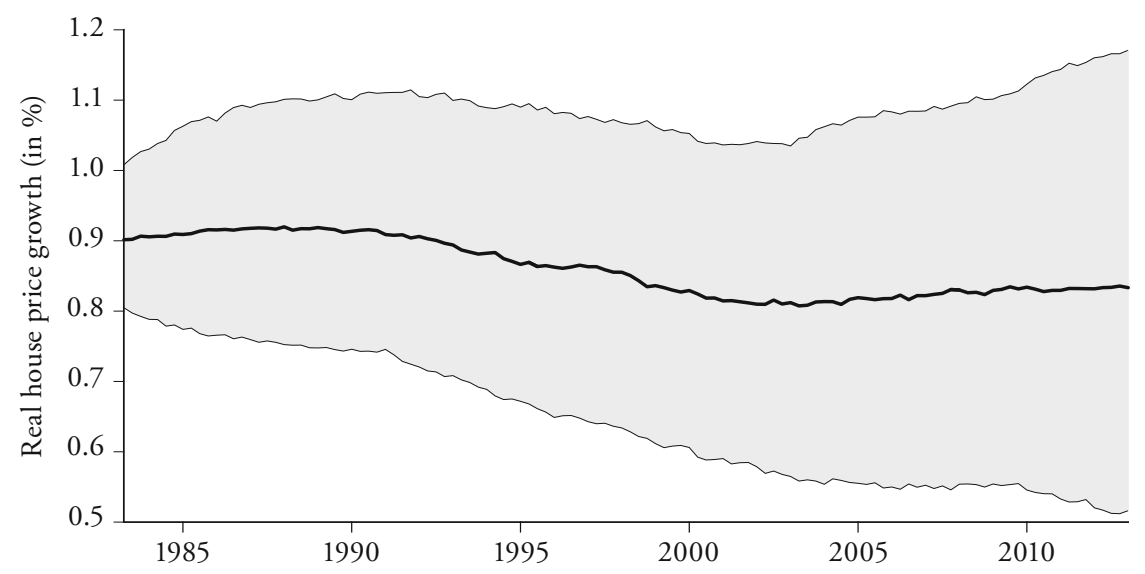

Notes: This figure represents the movement of impulse responses over time, measured 5 quarters after the shock of house prices to a negative shock on the mortgage rate change (i. e. user costs). The magnitude of the shock is set to one standard deviation (4.8\%). The x-axis depicts the lags as in quarters. The ordinate displays the responses in percentage points. The results are based on the previously described use of a TVC-BVAR. The continuous line represents the median and the grey surface the error bands up to one standard deviation.

year), after five years the effect is still 0.3 percent in the median. ${ }^{22}$ The shape of the responses changes over time. While in the early 1990s interest rate related effects rapidly reduce in size within 2.5 years, since the early 2000 s the effects fade more slowly and smoothly.

Additionally, the size of the impulse responses diminishes over time. In the mid-1980s, the median quarterly house price growth (peak effect, observed after 5 quarters) was $0.9 \%$ above what would have been experienced without a one standard deviation shock in mortgage rate changes occurring. After the 1990s real estate crisis the peak median response (after 5 quarters) to a one standard deviation shock drops to $0.8 \%$ per quarter, indicating that a mortgage rate shock has less impact on house prices than it used to have in the 1980s (see Figure 9). This is a drop by roughly $10 \%$.

22 Such a persistence in responses has repeatedly been reported in the literature. BERLEMANN and FrEESE (2013) find that interest rate effects on different kind of housing are rather persistent, and lose their significance 3-4 years after the shock. The peak effect in levels is reached after 2 years. Assenmacher and Gerlach (2008) including Swiss data also find a persistent effect of interest rates on property prices on average in their panel VAR with 17 countries. 
Figure 10: Response of House Prices to a Shock on GDP Growth

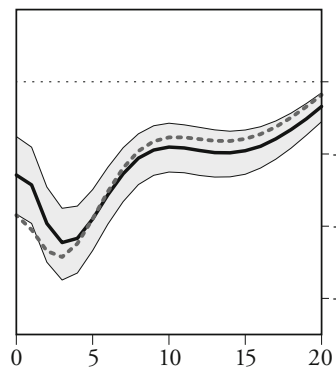

1987

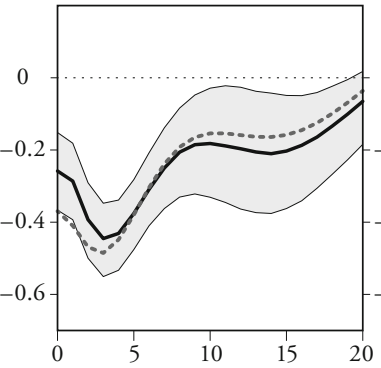

1999

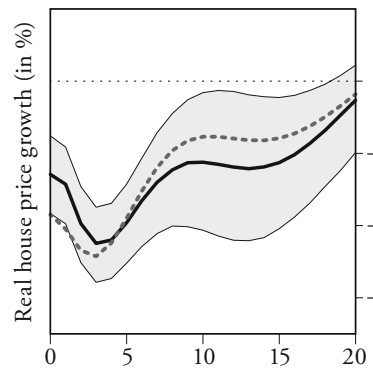

2007

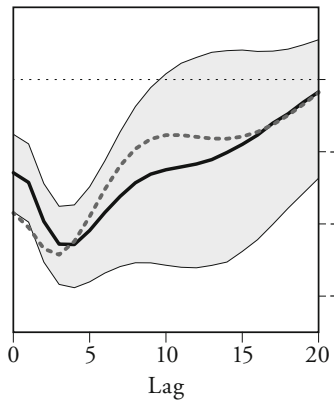

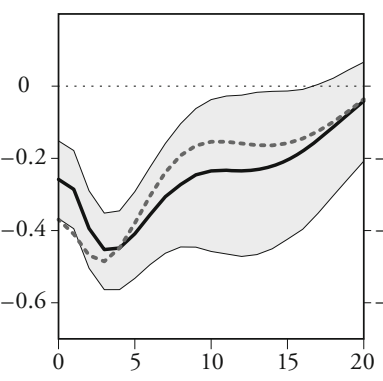

2011

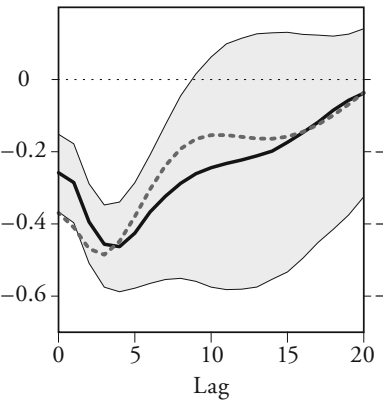

1991

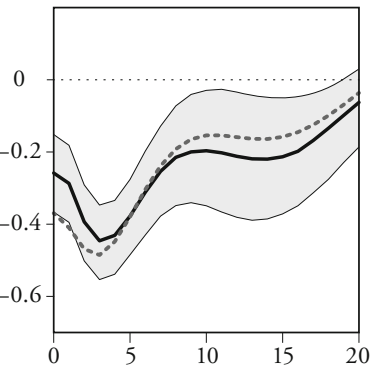

2003

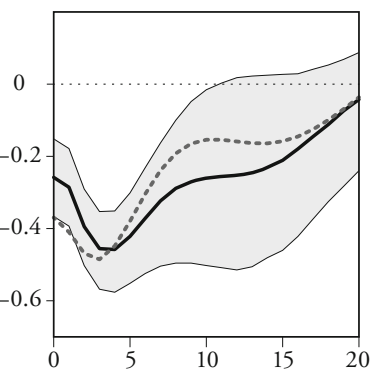

2013

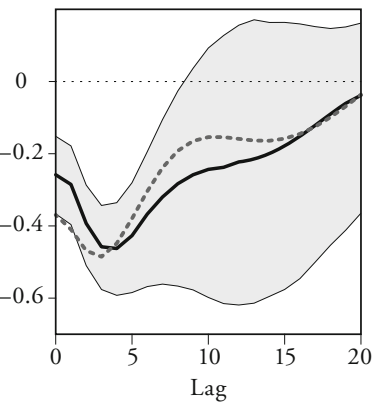

Notes: This figure represents the impulse response functions of the reaction of house prices to a negative shock in GDP growth. Such a shock could be caused by an unanticipated decline in GDP growth. The magnitude of the shock is set to one standard deviation (1.1\%). The $\mathrm{x}$-axis depicts the lags as in quarters. The ordinate displays the responses in percentage points. The results are based on the previously described use of a TVC-BVAR. Each plot refers to a specific observation point. For each point in time results a different impulse response function because of the time-varying estimation. The continuous lines represent the median and the grey surfaces the error bands up to one standard deviation. The grey dotted lines are the impulse response function after estimating a standard BVAR described in the text. 
Figure 11: Effect (after 8 Quarters) of House Price Responses to a Shock on GDP Growth

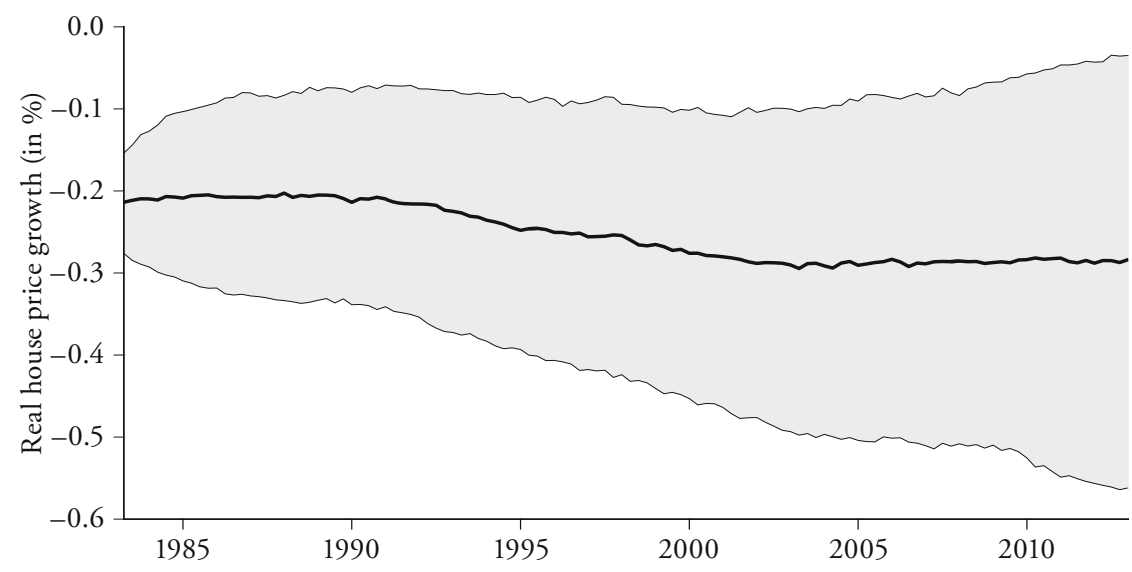

Notes: This figure represents the movement of impulse responses over time, measured 8 quarters after the shock of house prices to a negative shock on GDP growth. The magnitude of the shock is set to one standard deviation (1.1\%). The $\mathrm{x}$-axis depicts the lags as in quarters. The ordinate displays the responses in percentage points. The results are based on the previously described use of a TVC-BVAR. The continuous line represents the median and the grey surface the error bands up to one standard deviation.

The explained variance of house prices by mortgage rate innovations increases to $20 \%$ prior to the 1990 s real estate crisis, and decreases in the median to $18 \%$ at the turn of the century (see Figure 6). Hence, the population adjusted housing supply growth accounts for a much higher share of house prices variation than the mortgage rate change. Furthermore, the impact of population adjusted housing supply growth on house prices is more stable over time than the effect of mortgage rate change.

Orthogonal negative innovations to GDP growth have as expected a negative effect on house price developments (Figure 10). The impact is the highest after one year $(-0.5 \%)$ and is quite persistent (standard BVAR). The persistence of the GDP shock increases over time. During the 1980s/early 1990s, a GDP shock affects house prices very similar to the estimated standard BVAR. The GDP shocks become more persistent after the real estate crisis with a higher impact about a year after the shock. This is visible when plotting the effect on house prices after 8 quarters (Figure 11). During the real estate boom, the median effect on house prices after 8 quarters was about $-0.21 \%$ which drops to about 
$-0.28 \%$. The explained forecast error variance of house prices by GDP is low and fluctuates around $5 \%{ }^{23}$

\subsection{Heterogeneity in Housing Segments}

It seems that during the 1980s real estate boom, house prices reacted more strongly to shocks on the mortgage rate change and on population adjusted housing supply growth than after the bust. The effects of GDP growth on house prices are stronger after the real estate crisis. It is possible to argue that the effects are constant since the early 2000s. Nevertheless, the picture changes completely by looking at owner-occupied apartment prices exclusively. We have estimated the TVC-BVAR by using the apartment price index instead of a weighted house price index. First, the peak effect (after 5 quarters) of a mortgage rate shock on apartment prices is higher than on house prices (Figure 12). Second, the effect is much more time varying by dropping from $1.1 \%$ in 1992 to $0.8 \%$ in $2002-\mathrm{a}$ relative drop by $30 \%$. Most importantly, the peak effect rises again afterwards to about $1 \%$ in 2010 and remains constant thereafter. The impact of shocks to population adjusted housing supply growth and to GDP growth on apartment prices also varies more strongly over time than their effect on house prices. Consequently, while focusing on a total house price index, important dynamics of apartment prices are hidden. The mortgage rate change is much more relevant for Swiss apartment markets in the 2010s than they used to be in earlier years. ${ }^{24}$

23 Other studies also Tsatsaronis and Zhu (2004) find (on average) no substantial effect of GDP on house prices. For group 1 countries (where Switzerland belongs to) Tsatsaronis and ZHU (2004) also only find an explained variance of $5 \%$ and less. Goodhart and Hofmann (2008) find on average no effect during normal times and significant responses during house price peaks using a panel VAR. Also Assenmacher and Gerlach (2008) only find a minor explanatory power for GDP on property prices using a panel VAR.

24 The effect of fundamentals on single family home prices and rented apartments are more stable over time. However, the dynamics are very different to owner-occupied apartment prices. The population adjusted housing supply growth and the mortgage rate have a stronger effect on single family house prices, while their impact on rented apartments is muted. Rented apartment prices react more strongly to a GDP shock, but all fundamentals explain much less of the variance. 
Figure 12: Peak Effect (after 5 Quarters) of Apartment Price Responses to a Shock on the Mortgage Rate Change (i.e. User Costs)

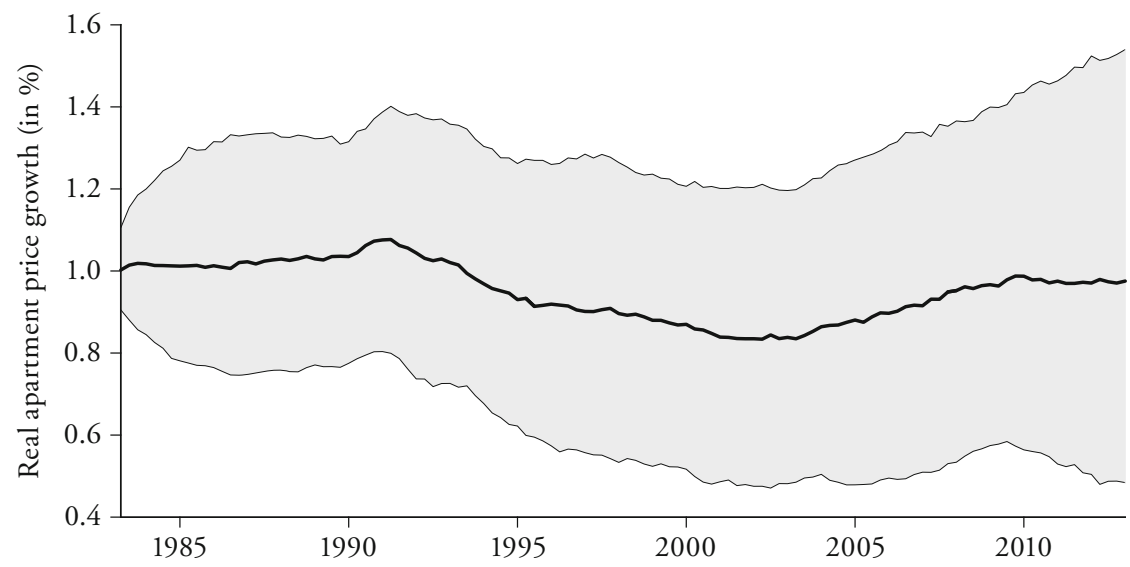

Notes: This figure represents the movement of impulse responses over time, measured 5 quarters after the shock of apartment prices to a negative shock on the mortgage rate change (i. e. user costs). The magnitude of the shock is set to one standard deviation (4.8\%). The $\mathrm{x}$-axis depicts the lags as in quarters. The ordinate displays the responses in percentage points. The results are based on the previously described use of a TVC-BVAR. The continuous line represents the median and the grey surfece the error bands up to one standard deviation.

\subsection{Regional Developments}

House prices and especially the population adjusted housing supply growth vary significantly across regions in Switzerland. The Lake Geneva is the only region which had a higher population growth than housing stock growth on average in the past 15 years (Table 1). Particularly in Central Switzerland, Berne and Eastern Switzerland, the housing stock growth was higher than the population growth on average. Regions such as Central Switzerland, Southern Switzerland, the Lake Geneva or Zurich experienced the strongest house price increase. Economic conditions measured by the unemployment rate were more homogeneous across Switzerland in the last 15 years.

Interestingly, the correlation of population adjusted housing supply growth and house price growth is also very different among the regions. Lake Geneva is the only region with a negative correlation, while all other exhibit the expected positive correlation of up to 0.6 (Zurich and North West Switzerland). To shed light on regional effects we estimate a BVAR for every region individually using 
Table 1: Summary Statistics

\begin{tabular}{lcc|cc|cc}
\hline & \multicolumn{2}{c|}{$(1)$} & \multicolumn{2}{c|}{$(2)$} & \multicolumn{2}{c}{ (3) } \\
& Mean & St.Dev. & Mean & St.Dev. & Mean & St.Dev. \\
\hline Zurich & -0.365 & 3.892 & 3.213 & 0.857 & 2.178 & 2.734 \\
Eastern Switzerland & -4.575 & 2.166 & 2.306 & 0.616 & 1.341 & 2.165 \\
Central Switzerland & -5.064 & 2.182 & 1.987 & 0.590 & 2.339 & 3.346 \\
North West Switzerland & -3.361 & 3.211 & 2.774 & 0.699 & 0.984 & 1.906 \\
Berne & -4.561 & 1.803 & 2.260 & 0.614 & 1.120 & 1.718 \\
Southern Switzerland & -3.775 & 3.494 & 3.403 & 0.822 & 2.257 & 2.765 \\
Lake Geneva & 2.030 & 4.903 & 5.019 & 0.913 & 4.255 & 3.527 \\
Western Switzerland & -1.810 & 2.345 & 3.303 & 0.844 & 1.737 & 1.830 \\
\hline
\end{tabular}

Notes: This table represents the summary statistics of the three variables population adjusted housing supply growth (1), unemployment rate (2) as well as house prices (3).

the same prior as before. ${ }^{25}$ As a benchmark, we use a BVAR using data from Switzerland with the same variables, time frame, prior and lag length. This allows to analyze the interplay of housing demand and supply, mortgage rates, the economic condition and house prices on a disaggregated level.

Figure 13 illustrates the response of house prices to a negative shock on population adjusted housing supply growth in Switzerland, Zurich and Lake Geneva over the period of 5 years (10 lags). ${ }^{26}$ In Switzerland as a benchmark, house prices are quite unresponsive to population adjusted housing supply growth during this period. The effect fluctuates around zero. In comparison, the region Lake Geneva exhibits a strong and persistent effect of population adjusted housing supply growth on house prices with a peak effect of $-1 \%$ after 3-4 lags. In the region Zurich, house prices also respond, but quicker than in Lake Geneva. However, house prices feature a counter movement with an unexpected positive effect after 2.5 years.

25 The lag length is one to not lose more degrees of freedom given the short time horizon available. Given the data frequency of semi-annual data in the regional analysis, the lag length of one is comparable to the lag length of two used in the aggregate analysis with quarterly data.

26 A figure including the error bands of the impulse response functions for each region is presented in the appendix. 


\section{Figure 13: Regional Analysis: Response of House Prices to a Shock on Population Adjusted Housing Supply Growth}

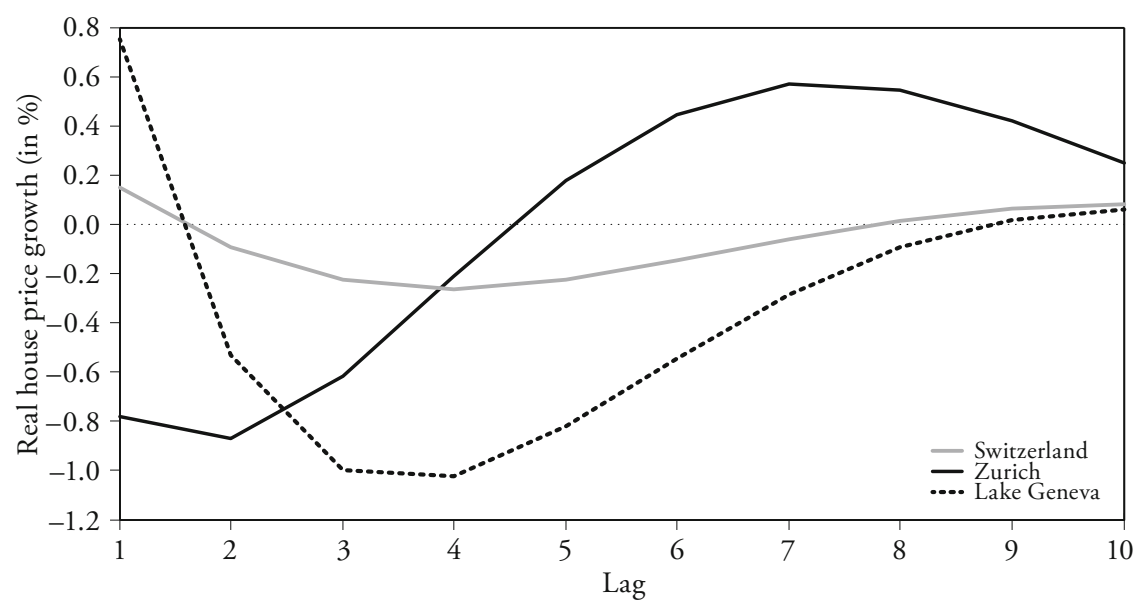

Notes: This figure represents the median impulse responses of the reaction of house prices to a negative shock on population adjusted housing supply growth. Such a shock could be caused by an unanticipated decline in population growth or by an unanticipated increase in construction of new apartments. The magnitude of the shock is standardized to the TVC-BVAR's shock. The $\mathrm{x}$-axis depicts the lags semi-annually measured. The ordinate displays the responses in percentage points. The results are based on the previously described estimation of a BVAR for the region of Zurich, Lake Geneva and Switzerland individually using semi-annual data from 1997 until 2013. The grey line refers to Switzerland, the dotted black line stands for Lake Geneva and the solid black line represents Zurich.

The impact of a negative mortgage rate shock on house prices is as expected positive in the beginning for the benchmark case of Switzerland, but soon turns negative (Figure 14). The reaction in the region Zurich shows a very similar pattern. However, house prices in Lake Geneva respond much more to a shock on mortgage rate changes. The effect is the biggest in the beginning with $0.8 \%$ and then declines, but stays positive. ${ }^{27}$

Turning to the effect of a negative shock on the unemployment rate (Figure 15), we would expect a rising house price. With a lower unemployment rate (better economic conditions), house prices should feature a positive development. In

27 However, in Lake Geneva single family homes are quite unresponsive to a mortgage rate shock, while owner-occupied apartments and rented apartments do respond. 
Figure 14: Regional Analysis: Response of House Prices to a Shock on Mortgage Rate Change

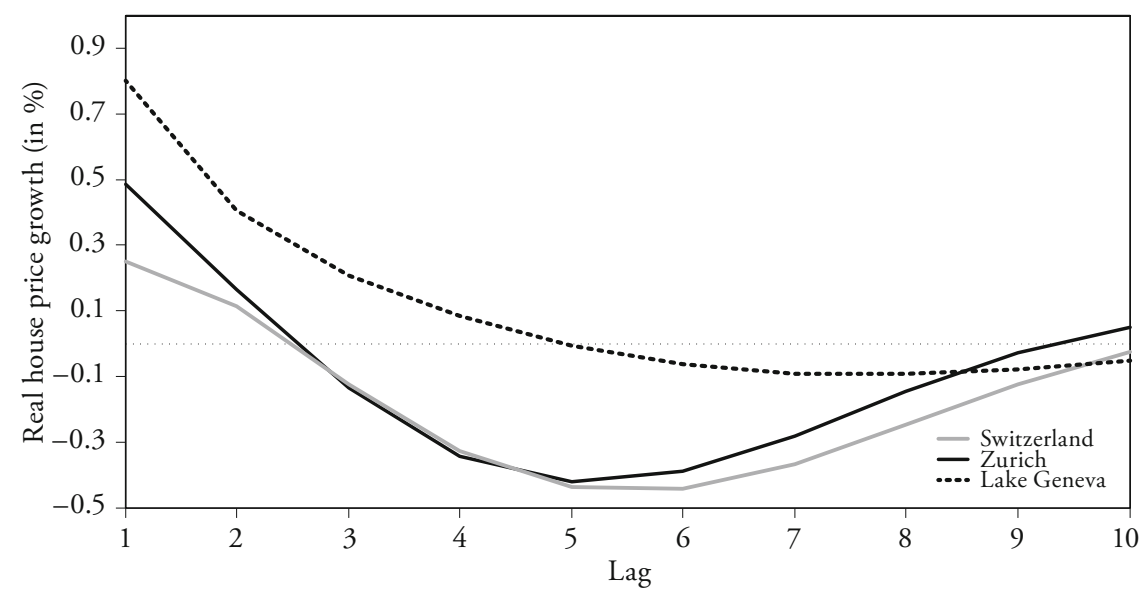

Notes: This figure represents the impulse response functions of the reaction of house prices to a negative shock on the mortgage rate change (i. e. user costs). Such a shock could be caused by an unanticipated decline in the change in the mortgage rate. The magnitude of the shock is standardized to the TVC-BVAR's shock. The $\mathrm{x}$-axis depicts the lags semi-annually measured. The ordinate displays the responses in percentage points. The results are based on the previously described estimation of a BVAR for the region of Zurich, Lake Geneva and Switzerland individually using semi-annual data from 1997 until 2013. The grey line refers to Switzerland, the dotted black line stands for Lake Geneva and the solid black line represents Zurich.

Switzerland, house prices respond as expected positively, with a peak effect of $1.4 \%$ after 4 lags. Again, Zurich exhibits a very similar pattern than the benchmark Switzerland. In the region Lake Geneva, house prices are not substantially affected by unemployment rate shocks. The effect fluctuates around zero. ${ }^{28}$

This shows, that heterogeneity in the reaction of house prices to fundamentals across Swiss regions is prevalent. In Lake Geneva, house prices are more sensitive to mortgage rate shocks and population adjusted housing supply growth. In the region of Zurich, the reaction to unemployment is more pronounced while the reaction to mortgage rate shocks is limited. ${ }^{29}$

28 In Lake Geneva, owner-occupied apartments and rented apartments are positively affected by unemployment rate shocks, while single family home prices react unexpectedly negative.

29 For the region Zurich, the same results hold, if the three different house price indices are used individually in the regression. 
Figure 15: Regional Analysis: Response of House Prices to a Shock on the Unemployment Rate

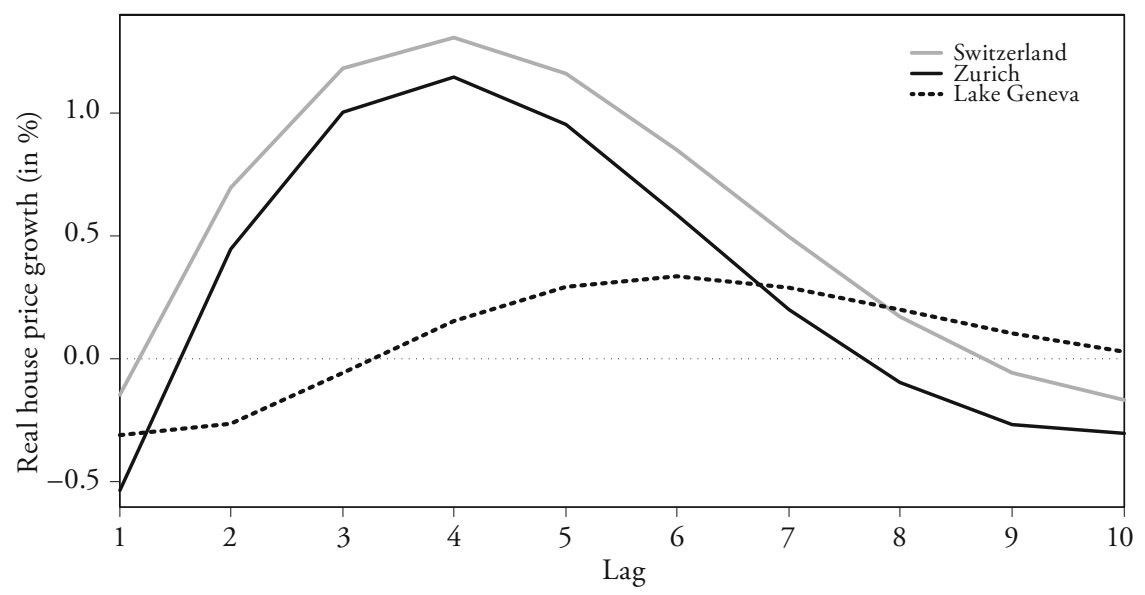

Notes: This figure represents the impulse response functions of the reaction of house prices to a negative shock on the unemployment rate. Such a shock could be caused by an unanticipated decline in the unemployment rate. The magnitude of the shock is standardized to the TVC-BVAR's shock. The $\mathrm{x}$-axis depicts the lags semi-annually measured. The ordinate displays the responses in percentage points. The results are based on the previously described estimation of a BVAR for the region of Zurich, Lake Geneva and Switzerland individually using semi-annual data from 1997 until 2013. The grey line refers to Switzerland, the dotted black line stands for Lake Geneva and the solid black line represents Zurich.

\section{Conclusion}

Swiss house prices have risen strongly in the last decade. We studied the importance of determinants of changes in house prices for Switzerland over time as well as across housing segments and regions. The variables under investigation were user costs (or financing conditions) expressed by the mortgage rate change, population adjusted housing supply growth and economic growth.

We find that any unanticipated change in mortgage rates or the population adjusted housing supply growth continue to matter and will most likely affect house price developments strongly. While aggregate values display dynamics over time, important (time-varying) dynamics of sub-components and between regions are hidden and can be retrieved by looking at regional effects and specific developments of housing sub-segments. 
Residential house prices react significantly to changes of fundamentals. The population adjusted housing supply growth is with $50 \%$ of house price variation by far more important than mortgage rate developments. In comparison to mortgage rate and supply/demand effects, GDP growth matters only marginally for explaining house price developments. Comparing the house price booms of the 1980s and the recent boom since the mid-2000s, mortgage rates had a stronger impact on house prices in the 1980s, while the effect has remained constant in recent decades. The impact of population adjusted housing supply growth is more stable over time.

Looking into housing segments, apartment prices also reacted more strongly to the mortgage rate change during the real estate bubble of the 1980s than during the real estate crisis in the 1990s. In contrast to total house prices, apartment prices became more sensitive to shocks to mortgage rates during the 2000 s/2010s house price boom. The respective impulse responses start to resemble the curvature of the late 1980s and early 1990s prior to the last Swiss real estate crisis.

House prices in Swiss regions react heterogeneously to shocks on fundamentals. The regions of Zurich and Lake Geneva with the strong population influx are vulnerable to changes in supply and demand for housing. While region Zurich also reacts strongly to economic condition, the region Lake Geneva is more responsive to mortgage rate changes. Policy makers should be aware about the effects and elasticities of changes in fundamentals and regional developments.

Such findings are highly relevant for the current situation in Switzerland, where mortgage rates have reached all-time lows. At the same time stricter criteria on mortgage lending most likely will increase the average effective mortgage rate to be paid by households. Housing production declines, but not as much as population growth might slow down in the next years caused by weaker job market conditions. In addition, more restrictive immigration policy (anti-mass immigration initiative), to be in place by 2017 , might dampen population growth.

\section{Appendix}

Figure 16 displays the peak effect of a one standard deviation negative shock in mortgage rates measured in levels on apartment prices over time. As can be seen the median impulse response is the largest in the 1980s and in the early 2000s. The value is reaching a trough in 1993 to 1995 and again in 2010. In the years before 1989 lower mortgage rates were followed by an increase in apartment prices, peaking five quarters later (Figure 17). The decline in mortgage rates from $6.5 \%$ in 1982 down to $5 \%$ in the mid 1980 s was accompanied by a strong 
increase in apartment prices. Also for the opposite direction a negative correlation was prevalent in the late 1980s. The increase of mortgage rates from $5 \%$ to $8 \%$ was followed by a strong decline in apartment prices. The correlation turned its sign in 1993 from negative to positive when mortgage rates were lowered from $8 \%$ to $5.5 \%$, yet apartment prices continued to decline nevertheless (one reason might be the expansion of housing stock during this period as a consequence of construction subsidies introduced in 1993).

The state equation parameters (time-varying coefficients) are linked to each other via a random walk. Movement of parameter values from one point in time to the consecutive one are restricted in size to guarantee stability of the process. Thereby movements of impulse responses from one point in time to the next are also restricted. If the correlation sign changes from negative to positive the impulse response moves towards a negative region. Once the correlation is reverted, the impulse response increases again. So in the 1990s the impulse response for a negative shock moved towards zero and negative regions due to the positive correlation prevalent between mortgage rates and apartment prices during the 1990s. Lower mortgage rates followed by substantially recovering apartment prices in the early 2000s resulted in a negative correlation and in rising parameter values. Due to a small reduction in mortgage rates being followed by a substantial increase in apartment prices the impulse response reaches its maximum value again.

Even though mortgage rates remained between $3 \%$ and $4.5 \%$ during the 2000s, apartment prices were almost stagnating between 2003 and 2006/2007, leading to a low correlation between mortgage rates and apartment prices during this time period. Consequently the impulse response median value declined to its trough. Since 2010/2011 impulse response values are increasing again. Yet, the impulse response values remain comparatively low, even though one might expect a stronger reaction given the low interest rate regime and the increasing apartment prices observed in the late 2000s, early 2010s. This puzzle can be explained by comparing apartment price growth in the last decade with the 1980s. The 1980s have shown a rapid increase of apartment prices even though mortgage rate levels were high. From 2007 until 2013, the apartment price growth was equally high as in the late 1980s, but the mortgage rate level was significantly lower. Therefore, in comparison the recent apartment price growth was only moderate given the current low mortgage rates, leading to smaller impulse responses. 
Figure 16: Peak Effect (after 5 Quarters) of Apartment Price Responses to a Shock of Mortgage Rate Level

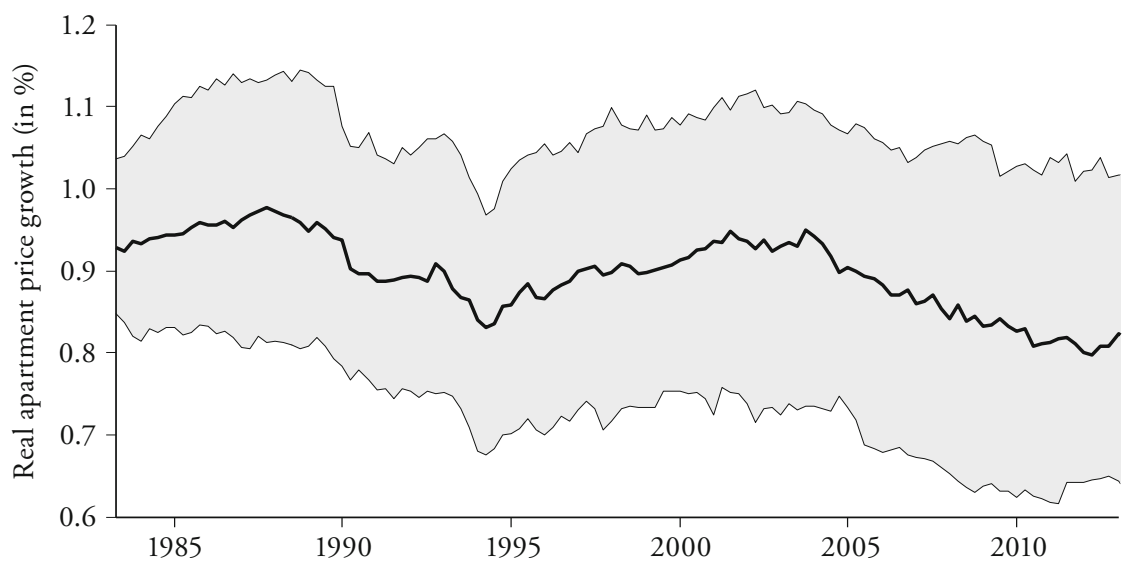

Notes: This figure represents the movement of impulse responses over time, measured 5 quarters after the shock of apartment prices to a negative shock in mortgage rates (level). The magnitude of the shock is set to one standard deviation. The x-axis depicts the lags as in quarters. The ordinate displays the responses in percentage points. The results are based on the previously described use of a TVC-BVAR. The continuous line represents the median and the grey surface the error bands up to one standard deviation.

Figure 17: Swiss Apartment Price Growth and Mortgage Rate

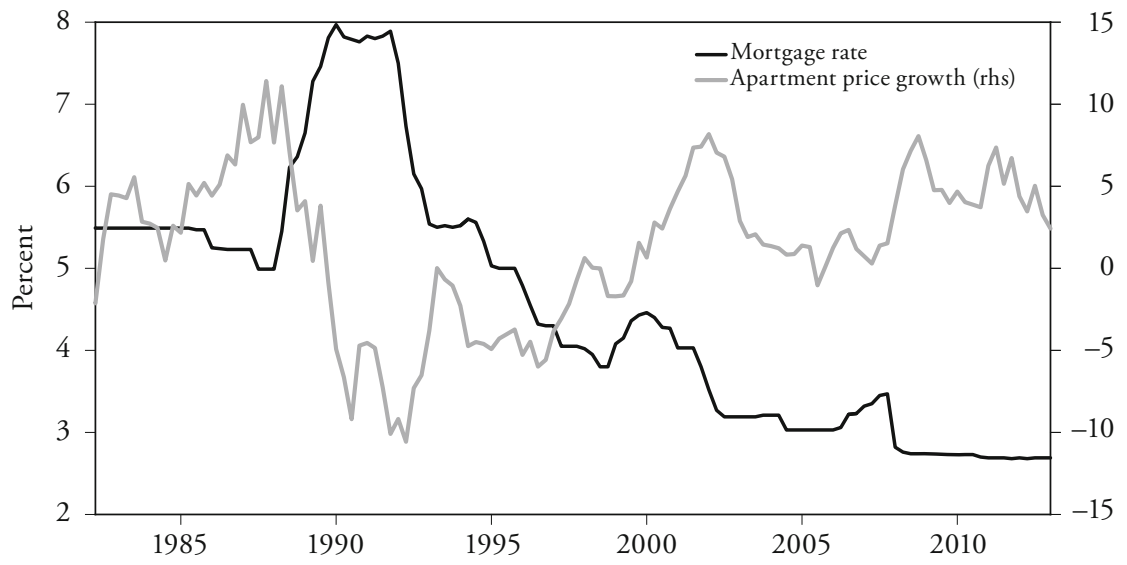

Notes: The figure displays the quarterly development of apartment price growth and the mortgage rate from Q1 1983 to Q4 2013. The y-axis displays values in percentage terms. The black line illustrates the mortgage rate. The grey line displays apartment price growth and is indexed on the right hand scale. 
Figure 18: Regional Analysis: Response of House Prices to a Shock on Fundamentals
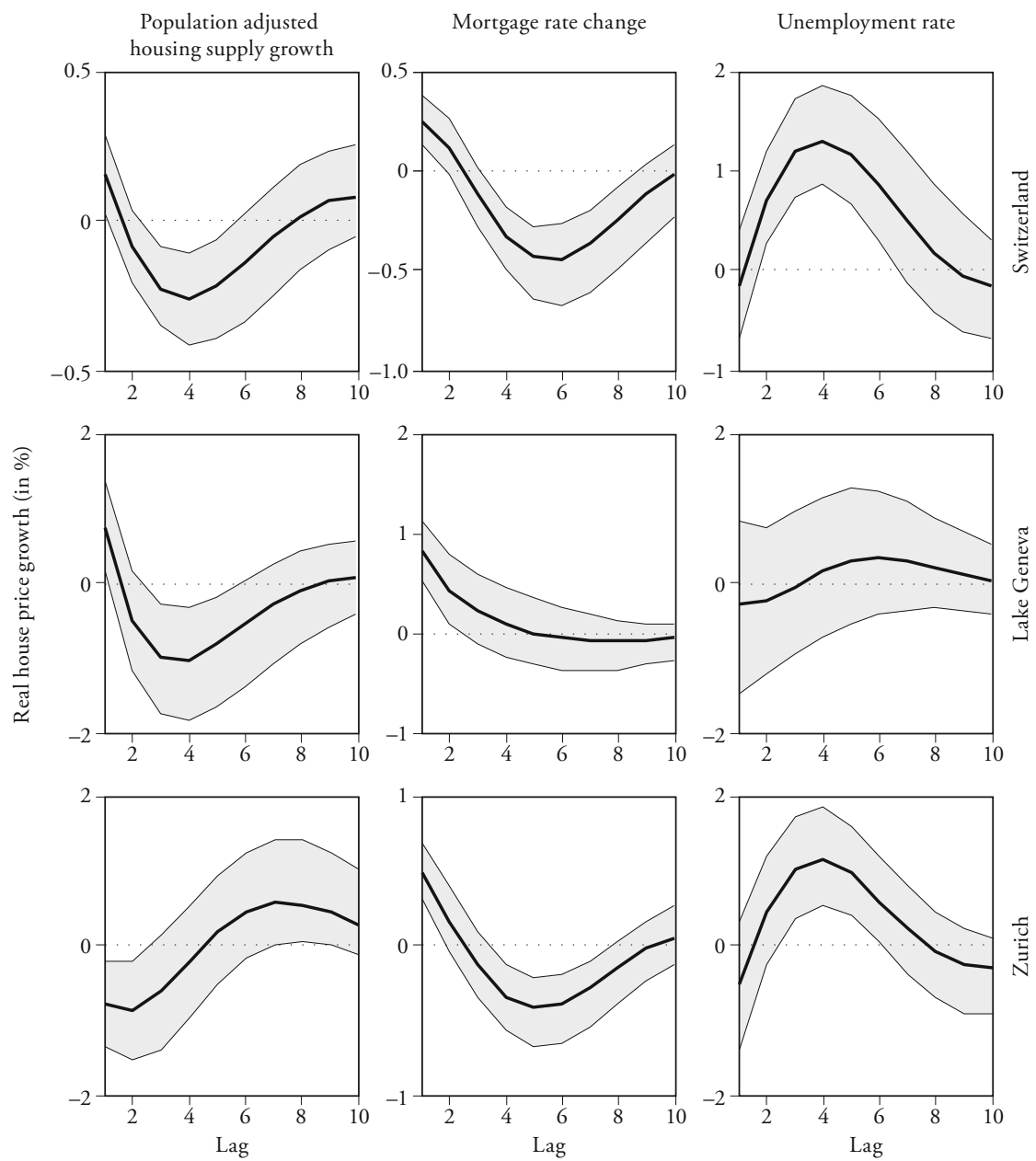

Notes: This figure represents the impulse response functions of the reaction of house prices to a negative shock on population adjusted housing supply growth, mortgage rate change as well as the unemployment rate (columns). The magnitude of the shocks is standardized to the TVC-BVAR's shocks. The $\mathrm{x}$-axis depicts the lags semi-annually measured. The ordinate displays the responses in percentage points. The results are based on the previously described estimation of a BVAR for the region of Zurich, Lake Geneva and Switzerland individually using semi-annual data from 1997 until 2013. The rows refer to the different regions (Switzerland, Lake Geneva, respectively Zurich). The continuous line represents the median and the grey surface the error bands up to one standard deviation. 


\section{References}

Assenmacher, Katrin, and Stefan Gerlach (2008), "Monetary Policy, Asset Prices and Macroeconomic Conditions: A Panel-VAR Study", Working Paper 149, National Bank of Belgium.

Basten, Christoph, and Catherine Koch (2015), "The Causal Effect of House Prices on Mortgage Demand and Mortgage Supply: Evidence from Switzerland”, Journal of Housing Economics, 30, pp. 1-22.

Belke, Ansgar, and Walter Orth (2007), "Global Excess Liquidity and House Prices - A VAR Analysis for OECD Countries”, Ruhr Economic Papers, 37, Rheinisch-Westfälisches Institut für Wirtschaftsforschung.

Berlemann, Michael, and Julia Freese (2013), "Monetary Policy and Real Estate Prices: A Disaggregated Analysis for Switzerland", International Economics and Economic Policy, 10(4), pp.469-490.

Borowiecki, Karol Jan (2009), "The Determinants of House Prices and Construction: An Empirical Investigation of the Swiss Housing Economy", International Real Estate Review, 12(3), pp. 193-220.

Bourassa, Steven Martin Hoesli, and Donato Scognamiglio (2010), "Housing Finance, Prices, and Tenure in Switzerland", Journal of Real Estate Literature, 18(2), pp. 263-282.

Brown, Martin, and Benjamin Guin (2013), How Risky are Residential Mortgages in Switzerland?, Swiss Institute of Banking and Finance.

Carter, Chris K., and Robert Kohn (1994), "On Gibbs Sampling for State Space Models", Biometrika, 81(3), pp. 541-553.

Credit Suisse (2015), "Real Estate Market 2015 - Structures and Prospects", March.

Degen, Kathrin, and Andreas M. Fischer (2010), "Immigration and Swiss House Prices”, Working Paper 16, Swiss National Bank.

Del Negro, Marco, and Frank Schorfheide (2011), "Bayesian Macroeconometrics", in The Oxford Handbook of Bayesian Econometrics, John Geweke, Gary Koop, and Herman van Dijk, eds., pp. 293-389, Oxford: Oxford University Press.

DiPasquale, Denise, and William C. Wheaton (1994), "Housing Market Dynamics and the Future of Housing Prices", Journal of Urban Economics, 35(1), pp. 1-27.

Gambetti, Luca (2005), "Technology Shocks and the Response of Hours Worked: Time-Varying Dynamics Matter", Manuscript, Universitat Pompeu Fabra, Barcelona, Spain. 
Goodhart, Charles, and Boris Hofmann (2008), "House Prices, Money, Credit, and the Macroeconomy", Oxford Review of Economic Policy, 24(1), pp. 180-205.

Hamilton, James Douglas (1994), Time Series Analysis, Cambridge University Press.

Hott, Christian, and Pierre Monnin (2008), "Fundamental Real Estate Prices: An Empirical Estimation with International Data", The Journal of Real Estate Finance and Economics, 36(4), pp.427-450.

Kim, Chang-Jin, and Charles R. Nelson (2003), State-Space Models with Regime Switching: Classical and Gibbs-Sampling Approaches with Applications, vol. 1, Cambridge: MIT Press Books.

Koop, Gary, and Dimitris Korobilis (2010), "Bayesian Multivariate Time Series Methods for Empirical Macroeconomics", Foundations and Trends in Econometrics, 3(4), pp. 267-358.

Müller-Jentsch, Daniel, and Lukas Rühli (2010), „Raumplanung zwischen Vorgabe und Vollzug: Inventar der kantonalen Instrumente zur Siedlungssteuerung", Kantonsmonitoring, Avenir Suisse.

Steiner, Elizabeth (2010), "Estimating a Stock-Flow Model for the Swiss Housing Market", Swiss Journal of Economics and Statistics, 146(3), pp. 601-627.

Tsatsaronis, Kostas, and Haibin Zhu (2004), "What Drives Housing Price Dynamics: Cross-Country Evidence”, BIS Quarterly Review, 3, pp. 65-78. 